\title{
Status, Trends, Challenges and the Bright Future of Solar Electricity from Photovoltaics
}

\section{Steven S. Hegedus ${ }^{1}$ and Antonio Luque ${ }^{2}$}

\author{
${ }^{1}$ Institute of Energy Conversion, University of Delaware, Newark, \\ Delaware, USA, ${ }^{2}$ Universidad Politecnica de Madrid, Madrid, Spain
}

\subsection{THE BIG PICTURE}

Congratulations! You are reading a book about a technology that has changed the way we think about energy. Solar electricity, also known as photovoltaics (PV), has shown since the 1970s that the human race can get a substantial portion of its electrical power without burning fossil fuels (coal, oil or natural gas) or creating nuclear fission reactions. Photovoltaics helps us avoid most of the threats associated with our present techniques of electricity production and also has many other benefits. Photovoltaics has shown that it can generate electricity for the human race for a wide range of applications, scales, climates, and geographic locations. Photovoltaics can bring electricity to a rural homemaker who lives 100 kilometers and 100 years away from the nearest electric grid connection in her country, thus allowing her family to have clean, electric lights instead of kerosene lamps, to listen to a radio, and to run a sewing machine for additional income. Or, photovoltaics can provide electricity to remote transmitter stations in the mountains allowing better communication without building a road to deliver diesel fuel for its generator. It can help a major electric utility in Los Angeles, Tokyo, or Madrid to meet its peak load on hot summer afternoons when air conditioners are working full time. It allows homes and businesses a new level of guaranteed energy availability and security, and photovoltaics has been powering satellites orbiting the Earth or flying to Mars for over 30 years.

Photovoltaics is an empowering technology that allows us to do totally new things, as well as, do old things better. It allows us to look at whole new modes of supplying 
electricity to different markets around the world and out of the world (in outer space). It also allows us to do what we already do (generate electricity, which is distributed over the transmission grid) but to do it in a sustainable, pollution-free, equitable fashion. Why is photovoltaics equitable? Because nearly every one has access to sunlight!

Electricity is the most versatile form of energy we have. It is what allows citizens of the developed countries to have nearly universal lighting on demand, refrigeration, hygiene, interior climate control in their homes, businesses and schools, and widespread access to various electronic and electromagnetic media. Access to and consumption of electricity is closely correlated with quality of life. Figure 1.1 shows the Human Development Index (HDI) for over 60 countries, which includes over 90\% of the Earth's population, versus the annual per capita electricity use (adapted from ref 1). The HDI is compiled by the UN and calculated on the basis of life expectancy, educational achievement, and per capita Gross Domestic Product. To improve the quality of life in many countries, as measured by their HDI, will require increasing their electricity consumption by factors of 10 or more, from a few hundred to a few thousand kilowatt-hrs (kWh) per year. How will we do it? Our choices are to continue applying the answers of the last century such as burning more fossil fuels (and releasing megatons of $\mathrm{CO}_{2}, \mathrm{SO}_{2}$, and $\mathrm{NO}_{2}$ ) or building more nuclear plants (despite having no method of safely disposing of the high-level radioactive waste) or to apply the new millennium's answer of renewable, sustainable, nonpolluting, widely available clean energy like photovoltaics and wind. (Wind presently generates over a thousand times more electricity than photovoltaics but it is very site-specific, whereas photovoltaics is generally applicable to most locations.)

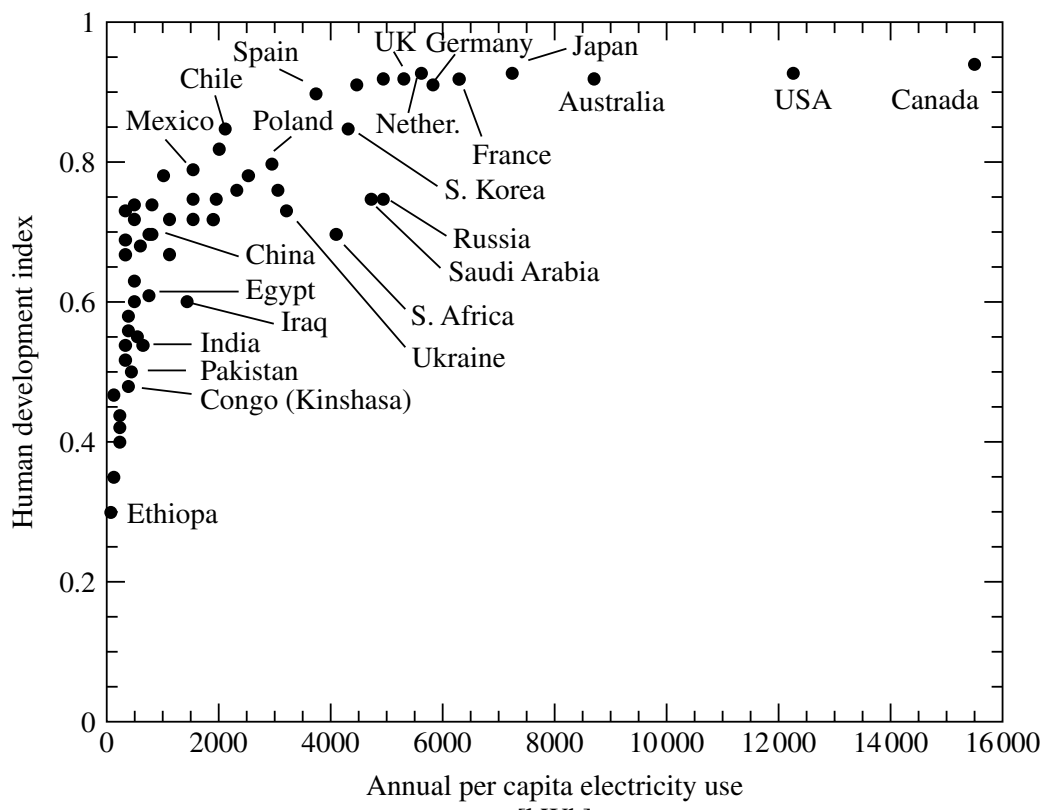

[kWh]

Figure 1.1 Human development index (HDI) vs. per capita kW usage [1] 


\subsection{WHAT IS PHOTOVOLTAICS?}

Photovoltaics is the technology that generates direct current (DC) electrical power measured in Watts $(\mathrm{W})$ or kiloWatts $(\mathrm{kW})$ from semiconductors when they are illuminated by photons. As long as light is shining on the solar cell (the name for the individual PV element), it generates electrical power. When the light stops, the electricity stops. Solar cells never need recharging like a battery. Some have been in continuous outdoor operation on Earth or in space for over 30 years.

Table 1.1 lists some of the advantages and disadvantages of photovoltaics. Note, that they include both technical and nontechnical issues. Often, the advantages and disadvantages of photovoltaics are almost completely opposite of conventional fossil-fuel power plants. For example, fossil-fuel plants have disadvantages of: a wide range of environmentally hazardous emissions, parts which wear out, steadily increasing fuel costs, they are not modular (deployable in small increments), and they suffer low public opinion (no one wants a coal burning power plant in their neighborhood). Photovoltaics suffers none of these problems. The two common traits are that both PV and fossil fueled power plants are very reliable but lack the advantage of storage.

Notice that several of the disadvantages are nontechnical but relate to economics and infrastructure. They are partially compensated for by a very high public acceptance and awareness of the environmental benefits. During the late 1990s, the average growth rate of PV production was over $33 \%$ per annum.

What is the physical basis of PV operation? Solar cells are made of materials called semiconductors, which have weakly bonded electrons occupying a band of energy

Table 1.1 Advantages and disadvantages of photovoltaics

Advantages of photovoltaics

Fuel source is vast and essentially infinite

No emissions, no combustion or radioactive fuel for disposal (does not contribute perceptibly to global climate change or pollution)

Low operating costs (no fuel)

No moving parts (no wear)

Ambient temperature operation (no high temperature corrosion or safety issues)

High reliability in modules ( $>20$ years)

Modular (small or large increments)

Quick installation

Can be integrated into new or existing building structures

Can be installed at nearly any point-of-use

Daily output peak may match local demand

High public acceptance

Excellent safety record
Disadvantages of photovoltaics

Fuel source is diffuse (sunlight is a relatively low-density energy)

High installation costs

Poorer reliability of auxiliary (balance of system) elements including storage

Lack of widespread commercially available system integration and installation so far Lack of economical efficient energy storage 
called the valence band. When energy exceeding a certain threshold, called the band gap energy, is applied to a valence electron, the bonds are broken and the electron is somewhat "free" to move around in a new energy band called the conduction band where it can "conduct" electricity through the material. Thus, the free electrons in the conduction band are separated from the valence band by the band gap (measured in units of electron volts or $\mathrm{eV}$ ). This energy needed to free the electron can be supplied by photons, which are particles of light. Figure 1.2 shows the idealized relation between energy (vertical axis) and the spatial boundaries (horizontal axis). When the solar cell is exposed to sunlight, photons hit valence electrons, breaking the bonds and pumping them to the conduction band. There, a specially made selective contact that collects conduction-band electrons drives such electrons to the external circuit. The electrons lose their energy by doing work in the external circuit such as pumping water, spinning a fan, powering a sewing machine motor, a light bulb, or a computer. They are restored to the solar cell by the return loop of the circuit via a second selective contact, which returns them to the valence band with the same energy that they started with. The movement of these electrons in the external circuit and contacts is called the electric current. The potential at which the electrons are delivered to the external world is slightly less than the threshold energy that excited the electrons; that is, the band gap. Thus, in a material with a $1 \mathrm{eV}$ band gap, electrons excited by a $2 \mathrm{eV}$ photon or by a $3 \mathrm{eV}$ photon will both still have a potential of slightly less than $1 \mathrm{~V}$ (i.e. the electrons are delivered with an energy of $1 \mathrm{eV}$ ). The electric power produced is the product of the current times the voltage; that is, power is the number of free electrons times their potential. Chapter 3 delves into the physics of solar cells in much greater detail.

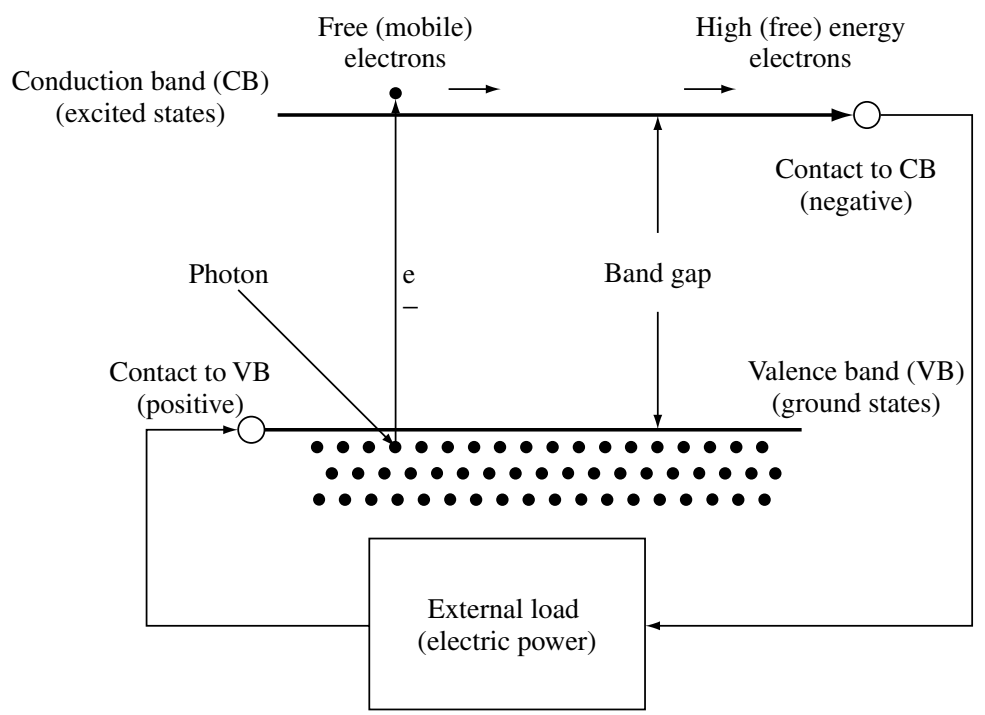

Figure 1.2 Schematic of a solar cell. Electrons are pumped by photons from the valence band to the conduction band. There they are extracted by a contact selective to the conduction band (an $n$-doped semiconductor) at a higher (free) energy and delivered to the outside world via wires, where they do some useful work, then are returned to the valence band at a lower (free) energy by a contact selective to the valence band (a $p$-type semiconductor) 
Sunlight is a spectrum of photons distributed over a range of energy. Photons whose energy is greater than the band gap energy (the threshold energy) can excite electrons from the valence to conduction band where they can exit the device and generate electrical power. Photons with energy less than the energy gap fail to excite free electrons. Instead, that energy travels through the solar cell and is absorbed at the rear as heat. Solar cells in direct sunlight can be somewhat $\left(20-30^{\circ} \mathrm{C}\right)$ warmer than the ambient air temperature. Thus, PV cells can produce electricity without operating at high temperature and without mobile parts. These are the salient characteristics of photovoltaics that explain safe, simple, and reliable operation.

At the heart of any solar cell is the pn junction. Modeling and understanding is very much simplified by using the $p n$ junction concept. This $p n$ junction results from the "doping" that produces conduction-band or valence-band selective contacts with one becoming the $n$-side (lots of negative charge), the other the $p$-side (lots of positive charge). The role of the pn junction and of the selective contacts will be explained in detail in Chapters 3 and 4. Here, pn junctions are mentioned because this term is often present when talking of solar cells, and is used occasionally in this chapter.

Silicon ( $\mathrm{Si}$ ), one of the most abundant materials in the Earth's crust, is the semiconductor used in crystalline form (c-Si) for $90 \%$ of the PV applications today (Chapter 5). Surprisingly, other semiconductors are better suited to absorb the solar energy spectrum. This puzzle will be explained further in Section 1.10. These other materials are in development or initial commercialization today. Some are called thin-film semiconductors, of which amorphous silicon (a-Si) (Chapter 12), copper indium gallium diselenide $\left(\mathrm{Cu}(\mathrm{InGa}) \mathrm{Se}_{2}\right.$ or CIGS) (Chapter 13), and cadmium telluride (CdTe) (Chapter 14) receive most of the attention. Solar cells may operate under concentrated sunlight (Chapter 11) using lenses or mirrors as concentrators allowing a small solar cell area to be illuminated with the light from larger area. This saves the expensive semiconductor but adds complexity to the system, since it requires tracking mechanisms to keep the light focused on the solar cells when the sun moves in the sky. Silicon and III-V semiconductors (Chapter 9), made from compounds such as gallium arsenide (GaAs) and gallium indium phosphide (GaInP) are the materials used in concentrator technology that is still in its demonstration stage.

For practical applications, a large number of solar cells are interconnected and encapsulated into units called PV modules, which is the product usually sold to the customer. They produce DC current that is typically transformed into the more useful AC current by an electronic device called an inverter. The inverter, the rechargeable batteries (when storage is needed), the mechanical structure to mount and aim (when aiming is necessary) the modules, and any other elements necessary to build a PV system are called the balance of the system (BOS). These BOS elements are presented in Chapters 17 to 19.

\subsection{SIX MYTHS OF PHOTOVOLTAICS}

Borrowing a format for discussing photovoltaics from Kazmerski [2], in this section, we will briefly present and then dispel six common myths about photovoltaics. In the following sections, we identify serious challenges that remain despite 40 years of progress in photovoltaics. 
The six myths are as follows:

1. Photovoltaics will require too much land area to ever meet significant fraction of world needs:

Solar radiation is a rather diffuse energy source. What area of PV modules is needed to produce some useful amounts of power? Let's make some very rough estimates to give answers that will be accurate within a factor of 2 . Using methods described in detail in Chapter 20 (especially equations 20.50 and 20.51 and Table 20.5), one can calculate how much sunlight falls on a square meter, anywhere in the world, over an average day or a year. We will use an average value of 4 kilowatt-hrs $(\mathrm{kWh})$ per $\mathrm{m}^{2}$ per day to represent a conservative worldwide average. Now, a typical PV module is approximately $10 \%$ efficient in converting the sunlight into electricity, so every square meter of PV module produces, on average, $4 \times 0.1=0.4 \mathrm{kWh}$ of electrical energy per day. We can calculate the area in $\mathrm{m}^{2}$ needed for a given amount of electrical energy $E$ in $\mathrm{kWh}$ by dividing $E$ by $0.4 \mathrm{kWh} / \mathrm{m}^{2}$. (Chapter 20 contains much more detailed methods to calculate the incident sunlight and the PV module output as a function of time of day, month of year, etc.)

Let us consider three different-sized PV applications: a family's house in an industrialized country, replacing a $1000 \mathrm{MW}$ (megawatt) coal or nuclear powered generating plant, or providing all the electricity used in the USA.

First, for a typical family, let us assume that there are four people in the house. Figure 1.1 shows a range of electricity usage for the industrialized countries. Let us use $6000 \mathrm{kWh} /$ person/year as an average. But, this includes all their electrical needs including at work, at school, as well as the electricity needed for manufacturing the products they buy, powering their street lights, pumping water to their homes, and so on. Since people spend about a third of the day awake in their home, let us assume that a third of their electrical needs are to be supplied in their home, or $2000 \mathrm{kWh} /$ person/year. Dividing this by 365 days in a year gives about $5 \mathrm{kWh} /$ person/day, or $20 \mathrm{kWh} /$ day per family of four. This is consistent with household data from various sources for the US and Europe. Thus, they would need $20 \mathrm{kWh} / 0.4 \mathrm{kWh} / \mathrm{m}^{2}$ or $50 \mathrm{~m}^{2}$ of solar modules to provide their electrical power needs over the year. Thus, a rectangular area of solar modules of 5 by 10 meters will be sufficient. In fact, many roofs are about this size, and many homes have sunny areas of this size around them, so it is possible for a family of four, with all the conveniences of a typical modern home, to provide all their power from PV modules on their house or in their yard.

Next, how much land would it take to replace a $1000 \mathrm{MW}$ coal or nuclear power plant that operates 24 hours/day and might power a large city? This would require $10^{6} \mathrm{~kW} \times 24 \mathrm{hr} /\left(0.4 \mathrm{kWh} / \mathrm{m}^{2}\right.$ ) or $6 \times 10^{7} \mathrm{~m}^{2}$. So, with $60 \mathrm{~km}^{2}$ (or 24 square miles) of photovoltaics we could replace one of last century's power plants with one of this century's power plants. This is a square $8 \mathrm{~km}$ (or 5 miles) on a side. For the same electricity production, this is equivalent to the area for coal mining during the coal powered plant's life cycle, if it is surface mining, or three times the area for a nuclear plant, counting the uranium mining area [3]. This is also the same area required to build a $600 \mathrm{~km}$ (373 miles) long highway (using a $100 \mathrm{~m}$ wide strip of land).

Finally, we can calculate how much land is needed to power the entire US with photovoltaics (neglecting the storage issue). The US used about $3.6 \times 10^{12} \mathrm{kWh}$ of electricity in 2000 . This could be met with $2 \times 10^{10} \mathrm{~m}^{2}$. If we compare with the area of paved roads across the country, of about $3.6 \times 10^{6} \mathrm{~km}$ and assume an average width 
of $10 \mathrm{~m}$ this leads to $3.6 \times 10^{10} \mathrm{~m}^{2}$. It is to be concluded that all the electricity needed in the US can be met by covering the paved roads with PV modules. Of course, no one is seriously proposing this action. We use the road analogy to show that if society wanted, it could establish land use priorities favorable to photovoltaics just as it has done to accommodate the ubiquitous automobile. We are certain that each state could find areas of unused land around airports, parking spaces, rooftops, highway dividing strips, or desert land that could be used for photovoltaics.

These simplistic "back-of-the-envelope" calculations show that having enough area for PV modules is not a limit for a homeowner or a large city. Certainly, there are sunny places in every country that could be used for generating significant amounts of PV power. As will be evident in other chapters, it is the initial cost of the photovoltaics, not the amount of land that is the primary barrier to be overcome.

2. Photovoltaics can meet all of the world's needs today if we would just pass laws requiring photovoltaics and halting all fossil and nuclear plants:

Besides the difficulty of convincing the people's representatives to pass such a law, the first technical problem faced would be the intermittent nature of the solar radiation, available only during the day and strongly reduced in overcast skies. Energy storage would solve this problem but no cheap storage method appears on the horizon. Nevertheless, well-developed electric grids may accept large amounts of PV electricity by turning off some conventional power plants when PV plants are delivering power. Adequate grid management would allow up to 20 to $30 \%$ of the electric production to be intermittent [4].

But now for a dose of reality. The cumulative production of PV modules up to the year 2002 is about $2000 \mathrm{MW}$. Thus, if you took all of the PV panels that were ever made up to and including the year 2002, and put them all in the same sunny place at the same time, they would generate enough electricity to displace about one of last century's $500 \mathrm{MW}$ smoke- or radioactive-waste-producing power plants. (This assumes that the solar plant would operate at full output for an equivalent of six hours per day owing to the daily variation in sunlight). Clearly, if we want photovoltaics to make any meaningful contribution to the world's energy supply, very massive increases in manufacturing capacity are needed. Additionally, PV electricity is very expensive, presently between 5 to 10 times more expensive than conventional alternatives. Mass use of PV electricity today could produce significant negative distortion of the economic system.

Thus, requesting the immediate and exclusive use of photovoltaics is not feasible technically or, probably, economically. It would also be socially unacceptable.

3. Photovoltaics cannot meet any significant fraction of world needs. It will remain a small-scale "cottage" industry that will only meet the needs of specialty markets like remote homes in developing countries or space satellites:

Figure 1.3 shows the evolution of markets associated with different applications [5]. Some used to be considered as specialty markets, for example, the category of "world off-grid power" which is trying to supply power to the $\sim 1 / 3$ of the world's citizens who lack it. The grid-connected market, whose growth has been meteoric in the past decade, is by no means a small market. Ironically it is the large-scale (recently awakened) centralized power plant market which is the smallest "specialty" application in today's world. Thus, evidence from the recent past tends to refute 


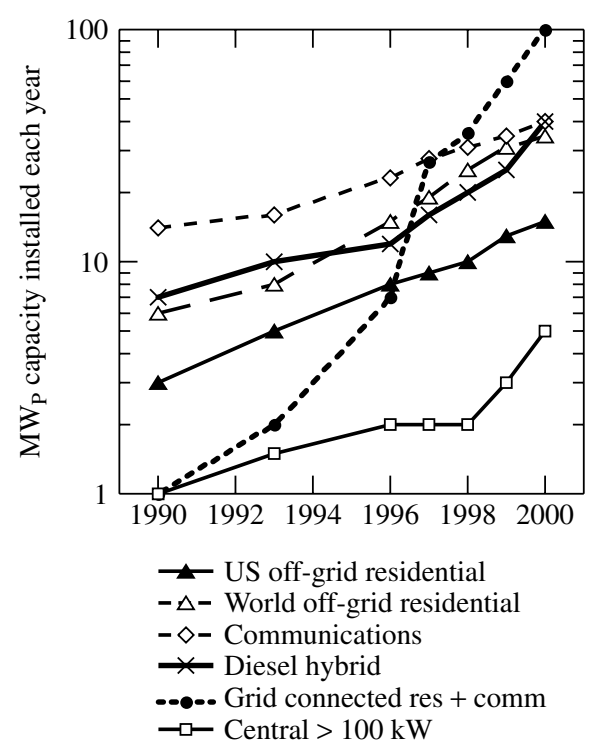

Figure 1.3 Trend in worldwide PV applications (From Reference [5] Maycock P, Renewable Energy World 3, 59-74 (2000)

the modest forecasts that some attribute to photovoltaics. We shall come to this point again.

4. No more $R / D$ is needed since $P V$ technology has demonstrated the technical capability to perform, so we should stop all public funding and let the economic markets decide if it is worthwhile:

The present cost of photovoltaics is affordable for certain markets but it is still too high to actually compete with conventional electricity. If PV technology is to be promoted for environmental or social reasons, public subsidy to $R \& D$ and to installation will be necessary to stimulate production and thereby reduce costs. Without continued subsidies, photovoltaics will probably remain as a specialty cottage industry for the next half century.

Public support for photovoltaics is one of the major factors compelling politicians to fund R\&D. This funding had been comparable to PV sales in the 1980s, as shown in Figure 1.4. Private funding has doubled this public support so that PV companies themselves have also heavily supported the development of photovoltaics. After two decades of constant investment in a promising market that was slow to actually start, the market finally awoke and became one of the fastest growing in the world by the beginning of the twentieth century, with sales now greatly exceeding public investment.

But, this fast growing market is still dependent on public/government funding. As with many goods and services (e.g. military hardware, commercial air travel), photovoltaics is partly publicly financed. In Germany or in Japan, for instance, significant public support is being given to grid-connected installations. If photovoltaics is going to become a major energy contender, the countries where the support has been lacking will remain technologically inferior with respect to those, where the support has 


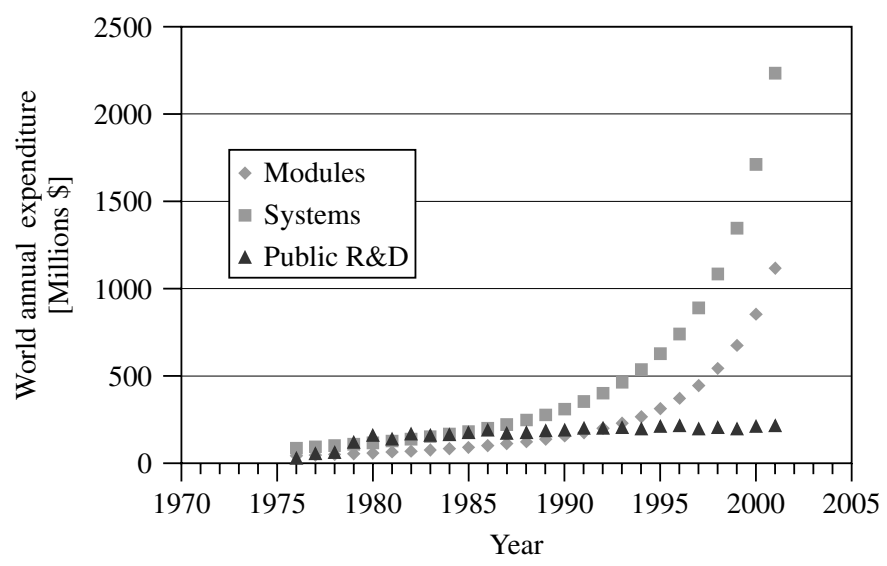

Figure 1.4 Public funding for R\&D (triangles) compared to module (diamonds) and system (squares) sales. (This curve is drawn from the data of Eckhart et al. in Chapter 24, "Financing PV Growth", in this book)

been stronger. This should be taken into account while making decisions about energy policy and public or private financing.

The critical question then is: Should the support be focused in R\&D, or is PV technology already mature enough (as many claim) to focus on the cost reduction via the economy of scale permitted by the larger volume of production required by a subsidized market? This point will be discussed latter in this chapter.

5. Photovoltaics is polluting just like all high-technology or high-energy industries only with different toxic emissions:

One of the most valuable characteristics of photovoltaics is its well-deserved image as an environmentally clean and "green" technology. This healthy image obviously results from the cleaner operation of a PV electricity generator compared to a fossil-fuel fired generator, but this must also extend to the manufacturing process itself as well as the recycling of discarded modules. Manufacturing of PV modules on a large scale requires the handling of large quantities of hazardous or potentially hazardous materials (e.g. heavy metals, reactive chemical solutions, toxic gases). Let it be stated at the beginning that the present Si-based PV technology which dominates the market has few environmental concerns and is considered totally safe to the public.

The PV industry is very aware of the value of its clean "green" image and has worked hard over the years to establish and maintain high standards of environmental responsibility [6, 7]. Conferences on PV Safety and Environmental Issues have been held since the late 1980s and their proceedings have been published $[8,9]$; the PV Environmental Health Safety Assistance Center at Brookhaven National Laboratory in New York, USA provides worldwide leadership in risk analysis and safety recommendations for the PV industry [10].

Safe handling procedures for some of the materials and processes were already well established from the integrated circuit or glass coating industries. But in the case of unique materials and processes, safety procedures had to be developed by the PV industry. This is especially true of the thin-film technologies [11]. The PV industry recognized early that being proactive and designing safety into the process, from the 
beginning, was the responsible thing to do and would ultimately result in reduced costs. The international nature of the PV industry introduces some variability in the standards which must be met.

Hazards can be classified by whether they affect workers at a PV manufacturing plant, customers with photovoltaics on or near their homes, or the public who consumes air and water near the PV plant. The population with greatest potential health risks are employees in PV manufacturing. Very little risk is associated with the public or the PV owner or installer. Among the most heavily studied issues unique to the PV industry is the potential toxicity of semiconductor CdTe and the safe usage of hydride gases $\mathrm{AsH}_{3}, \mathrm{SiH}_{4}, \mathrm{GeH}_{4}, \mathrm{PH}_{3}, \mathrm{~B}_{2} \mathrm{H}_{6}$, and $\mathrm{H}_{2} \mathrm{Se}$, which are used in the growth of GaAs, a-Si, a-SiGe, and $\mathrm{Cu}\left(\mathrm{InGa}_{\mathrm{n}} \mathrm{Se}_{2}\right.$ layers. There has been considerable research and risk analysis of CdTe as a PV material [12-14]. The general conclusion is that $\mathrm{CdTe}$ in modules does not pose a risk to the public. Similarly, procedures and hardware ensuring safe usage of the hydride gases listed above have been well established in both the electronics and PV industries [15].

Environmental monitoring of the workplace for hazardous levels in the air or on surfaces, and biological monitoring of the employee for evidence of exposure should be routine. Once the module is manufactured, the only way for the public to be exposed to hazardous materials existing in some kind of modules is by absorbing them via ingestion or inhalation. Accordingly, accidental human absorption is not at all likely. Even in event of a house fire, studies have shown that PV modules do not release any potentially hazardous materials [16].

A related issue is what to do with thin film PV modules at the end of their projected 25- to 30-year life. An excellent strategy is to recycle the modules. This solves two problems at once, namely, keeping potentially hazardous materials out of the environment and reducing the need for additional mining and/or refining of new materials. Semiconductor vendors have indicated a willingness to accept used modules, and to extract and purify the $\mathrm{CdTe}, \mathrm{CdS}$, or $\mathrm{Cu}(\mathrm{InGa}) \mathrm{Se}_{2}$ for resale and reuse $[17,18]$.

Thus, we can say with confidence that photovoltaics is nearly the cleanest and safest technology with which to generate electricity. It is especially true of the present Si technology.

6. PV modules never recover all of the energy required in making them, thus they represent a net energy loss:

The focus of photovoltaics is on generating energy (specifically electrical energy) with many beneficial characteristics as noted in Table 1.1. Among those who envision photovoltaics having an increasingly larger role in producing the world's electricity, there is awareness that photovoltaics must produce much more energy than was required to produce the PV system. Otherwise, it would be a net energy loss not a net energy source. The "energy payback" has been widely studied. It is described in terms of how many years the PV system must operate to produce the energy required for its manufacture. After the payback time, all of the energy produced is truly new energy.

This topic is discussed in Chapter 21. An excellent review has been given by Alsema [19]. In general, results of several studies have arrived at some general conclusions. Specific payback times have ranged from 3 to 5 years for crystalline Si and 1 to 4 years for thin films. For crystalline Si, forming the crystalline Si wafers is 
the major energy requirement. For thin films, the semiconductor layers are 100 times thinner, and deposited at $\sim 1000^{\circ} \mathrm{C}$ lower temperature, so their energy requirement is negligible, in comparison. Instead, it is the energy embodied in the glass or stainless steel substrate, which is the major energy sink. Also, a seemingly insignificant component, the cosmetic Al frame around the module, is responsible for a surprisingly large fraction of energy. In fact, this can be the dominant energy sink for thin-film a-Si or $\mathrm{Cu}(\mathrm{InGa}) \mathrm{Se}_{2}$ modules $[20,21]$. Although thin-film modules have a shorter energy payback, they also have lower efficiency, which means a larger BOS is needed to support the larger number of modules. Thus, a larger amount of energy is embodied in the BOS for thin-film photovoltaics compared to crystalline $\mathrm{Si}$ photovoltaics.

The case of concentrators is less studied, but again the use of semiconductor is reduced and the BOS becomes more important than even for the thin films because the concentrating structures are very massive. However, their efficiency is higher. In summary, we can guess that in this case the situation will be similar to the case of thin films.

\subsection{HISTORY OF PHOTOVOLTAICS}

The history of photovoltaics goes back to the nineteenth century, as shown in Table 1.2. The first functional, intentionally made PV device was by Fritts [22] in 1883. He melted Se into a thin sheet on a metal substrate and pressed a Au-leaf film as the top contact. It was nearly $30 \mathrm{~cm}^{2}$ in area. He noted, "the current, if not wanted immediately, can be either stored where produced, in storage batteries, ... or transmitted a distance and there used." This man foresaw today's PV technology and applications over a hundred years ago. The modern era of photovoltaics started in 1954 when researchers at Bell Labs in the USA accidentally discovered that $p n$ junction diodes generated a voltage when the room lights were on. Within a year, they had produced a $6 \%$ efficient Si pn junction solar cell [23]. In the same year, the group at Wright Patterson Air Force Base in the US published results of a thin-film heterojunction solar cell based on $\mathrm{Cu}_{2} \mathrm{~S} / \mathrm{CdS}$ also having $6 \%$ efficiency [24]. A year later, a $6 \%$ GaAs pn junction solar cell was reported by RCA Lab in the US [25]. By 1960, several key papers by Prince [26], Loferski [27], Rappaport and Wysoski [28], Shockley (a Nobel laureate) and Queisser [29], developed the fundamentals of $p n$ junction solar cell operation including the theoretical relation between band gap, incident spectrum, temperature, thermodynamics, and efficiency. Thin films of CdTe were also producing cells with $6 \%$ efficiency [30]. By this time, the US space program was utilizing Si PV cells for powering satellites. Since space was still the primary application for photovoltaics, studies of radiation effects and more radiation-tolerant devices were made using Li-doped Si [31]. In 1970, a group at the Ioffe Institute led by Alferov (a Nobel laureate), in the USSR, developed a heteroface GaAlAs/GaAs [32] solar cell which solved one of the main problems that affected GaAs devices and pointed the way to new device structures. GaAs cells were of interest due to their high efficiency and their resistance to the ionizing radiation in outer space. The year 1973 was pivotal for photovoltaics, in both technical and nontechnical areas. A significant improvement in performance occurring in 1973 was the "violet cell" having an improved short wavelength response leading to a $30 \%$ relative increase in efficiency over state-of-the-art Si cells [33]. GaAs heterostructure cells were also developed at IBM in 
Table 1.2 Notable events in the history of photovoltaics

- 1839 Becquerel (FR) discovered photogalvanic effect in liquid electrolytes

- 1873 Smith (UK) discovered photoconductivity of solid Se

- 1877 Adams and Day (UK) discover photogeneration of current in Se tubes; the first observation of PV effect in solids

- 1883 Fritts (US) makes first large area solar cell using Se film

- 1954 First 6\% efficient solar cells reported: Si (Bell Lab, USA) and $\mathrm{Cu}_{2} \mathrm{~S} / \mathrm{CdS}$ (Air Force, USA)

- 1955 Hoffman Electronics (USA) offers 2\% efficient Si PV cells at \$1500/W

- 1958 NASA Vanguard satellite with Si backup solar array

- 1959 Hoffman Electronics (USA) offers 10\% efficient Si PV cells

- 1963 Sharp Corp (JP) produces first commercial Si modules

- 1966 NASA Orbiting Astronomical Observatory launched with 1 kW array

- 1970 First GaAs heterostructure solar cells by Alferov, Andreev et al. in the USSR

- 1972 First PV conference to include a session on terrestrial applications (IEEE)

- 1973 A big year in photovoltaics: Worldwide oil crisis spurs many nations to consider renewable energy including photovoltaics; Cherry Hill Conference in USA (established photovoltaics' potential and legitimacy for government research funding); World's first solar powered residence (University of Delaware, USA) built with $\mathrm{Cu}_{2} \mathrm{~S}$ (not c-Si!) solar modules

- 1974 Project Sunshine initiated in Japan to foster growth of PV industry and applications; Tyco (USA) grows $2.5 \mathrm{~cm}$ wide Si ribbon for photovoltaics, first alternative to Si wafers

- 1975 First book dedicated to PV science and technology by Hovel (USA)

- 1980 First thin-film solar cell $>10 \%$ using $\mathrm{Cu}_{2} \mathrm{~S} / \mathrm{CdS}$ (USA)

- 1981350 kW Concentrator array installed in Saudi Arabia

- 1982 First 1 MW utility scale PV power plant (CA, USA) with Arco Si modules on 2-axis trackers

- 19846 MW array installed in Carrisa Plains CA, USA [35]

- 1985 A big year for high-efficiency Si solar cells: Si solar cell $>20 \%$ under standard sunlight (UNSW, Australia) [36] and $>25 \%$ under 200X concentration (Stanford Univ. USA) [37]

- 1986 First commercial thin-film power module, the a-Si G4000 from Arco Solar (USA)

- 1987 Fourteen solar powered cars complete the $3200 \mathrm{~km}$ World Solar Challenge race (Australia) with the winner averaging $70 \mathrm{kph}$

- $1994 \mathrm{GaInP/GaAs}$ 2-terminal concentrator multijunction > 30\% (NREL, USA) [38]

- 1995 "1000 roofs" German demonstration project to install photovoltaics on houses, which triggered the present favorable PV legislation in Germany, Japan and other countries

- 1996 Photoelectrochemical "dye-sensitized" solid/liquid cell achieves 11\% (EPFL, Switzerland) [39]

- 1997 Worldwide PV production reaches 100 MW per year

- $1998 \mathrm{Cu}(\mathrm{InGa}) \mathrm{Se}_{2}$ thin-film solar cell reaches 19\% efficiency (NREL, US) [40] comparable with multicrystalline Si. First concentrating array for space launched on Deep Space 1 by US (5 kW using high efficiency GaInP/GaAs/Ge triple junction cells)

- 1999 Cumulative worldwide installed photovoltaics reaches 1000 MW

- 2000 Olympics in Australia highlight wide range of PV applications, and the awarding of the first Bachelor of Engineering degrees in Photovoltaics and Solar Engineering (UNSW, Australia)

- 2002 Cumulative worldwide installed photovoltaics reaches $2000 \mathrm{MW}$. It took 25 years to reach the first $1000 \mathrm{MW}$ and only 3 years to double it; production of crystalline Si cells exceeds $100 \mathrm{MW}$ per year at Sharp Corp. (Japan). BP Solar ceases R\&D and production of a-Si and CdTe thin-film modules in USA ending $>20$ years of effort 
the USA having 13\% efficiency [34]. Also in 1973, a crucial nontechnical event occurred called the Cherry Hill Conference, named after the town in New Jersey, USA, where a group of PV researchers and heads of US government scientific organizations met to evaluate the scientific merit and potential of photovoltaics. The outcome was the decision that photovoltaics was worthy of government support, resulting in the formation of the US Energy Research and Development Agency, the world's first government group whose mission included fostering research on renewable energy, which ultimately became the US Dept. of Energy. Finally, in October 1973, the first World Oil Embargo was instituted by the Persian Gulf oil producers. This sent shock waves through the industrialized world, and most governments began programs to encourage renewable energy especially solar energy. Some would say this ushered in the modern age of photovoltaics and gave a new sense of urgency to research and application of photovoltaics in terrestrial applications.

In the 1980s, the industry began to mature, as emphasis on manufacturing and costs grew. Manufacturing facilities for producing PV modules from $\mathrm{Si}$ wafer $p n$ junction solar cells were built in the USA, Japan, and Europe. New technologies began to move out of the government, university and industrial laboratories, and into precommercialization or "pilot" line production. Companies attempted to scale up the thin-film PV technologies like a-Si and $\mathrm{CuInSe} \mathrm{S}_{2}$, which had achieved $>10 \%$ efficiency for small area $\left(1 \mathrm{~cm}^{2}\right)$ devices made with carefully controlled laboratory scale equipment. Much to their disappointment, they found that this was far more complicated than merely scaling the size of the equipment. Most large US semiconductor companies, gave up their R/D efforts (IBM, General Electric, Motorola) lacking large infusions of private or government support to continue. One common result was the purchase of American companies and their technologies by foreign companies. In 1990, the world's largest solar manufacturer was Arco Solar (CA, USA), owned by oil company Atlantic Richfield, which had c-Si and thinfilm a-Si in production and thin-film $\mathrm{CuInSe}_{2}$ in precommercialization. They were sold to the German firm Siemens and renamed Siemens Solar (in 2001, the Dutch company Shell Solar would buy Siemens, becoming another large internationally based company with multiple PV technologies in production). Also in 1990, Energy Conversion Devices (MI, USA) formed a joint venture called United Solar Systems Corp. with the Japanese manufacturer Canon to commercialize ECD's roll-to-roll triple-junction a-Si technology. In 1994, Mobil Solar Energy (MA, USA), which had developed a process for growing solar cells on Si ribbon (called the Edge defined film growth or EFG process) instead of more costly wafers, was sold to the German company ASE and renamed ASE Americas. The British solar company BP Solar acquired patents to electrodeposition of thin-film CdTe solar cells in 1989, when it's parent company purchased the American oil giant Standard Oil of Ohio. At the same time, it acquired the patents of the University of New South Wales (Australia) to fabricate the Laser-Grooved Buried-Grid (LGBG) cells, which became the most efficient silicon cells in fabrication. In 1996, it signed a license agreement with the Polytechnic University of Madrid (Spain) to exploit the Euclides concentration technology that used their LGBG cells as concentrator cells. In 1999, BP Solar acquired Solarex from Enron (another huge fossil-fuel energy company) that had crystalline and amorphous Si solar cell technology. Thus, BP Solar established themselves with manufacturing interests in all three technology options (standard Si wafers, thin films 
and concentrators). ${ }^{1}$ Meanwhile, the Japanese PV industry began to take off. Production of c-Si modules and intensive research on thin-film technology in Japan led to many innovative device designs, improved materials processing, and growing dominance in the world PV market.

Along with the maturing of the solar cell technology, the BOS needed to grow. Many products like inverters, which convert the DC power into AC power, and sun trackers had only limited application outside of a PV power system, so once again there was only limited technical and financial resources for development. In many system evaluations, the inverter was repeatedly identified as the weak link in terms of reliability and AC power quality [41]. Their costs have not fallen nearly as fast as those for the PV modules. While much effort and resources had been focused on the solar cell cost and performance, little attention had been paid to installation and maintenance costs. It was quickly discovered that there was room for much improvement.

An early development that helped many companies was to sell PV cells for consumer-sized, small-scale power applications. The solar-powered calculator, pioneered by Japanese electronics companies as a replacement for battery-powered calculators in the early 1980s, is the best-known example. This led to the early use of thin-film a-Si PV cells for various applications. Another example was solar-powered outdoor lighting. These novel consumer applications, where portability and convenience were more valued than low price, allowed the PV companies to maintain some small income while continuing to develop power modules.

Another application was the rural electrification of remote villages in an attempt to help roughly one-third of the world's citizens to gain access to a modest amount of modern communication and lighting. Most of these PV installations were very small, on the order of 10 to $40 \mathrm{~W}$ per household (100 times smaller than the "needs" of a modern home in the developed world.) Most of these installations were funded by some international aid agency. Reviews and follow-up studies of these programs have indicated very large failure rates, primarily due to lack of technical infrastructure [42], training, cultural misunderstandings, design of the payment structure, and other nontechnical reasons [43]. Rarely have the PV modules failed. Even with subsidies from the international agencies, the high initial cost of ownership (\$100-1000) was still a major barrier in much of the world where this represents a year's income for a family [44].

On the opposite end of the size scale were the MW-size PV plants installed by utilities in developed countries in the 1980s to evaluate their potential in two applications: as a peak-load-reduction technology, where the photovoltaics provides additional power primarily to meet the peak demand during the afternoon [45]; or as distributed generators, to reduce transmission and distribution losses [46]. Several American utilities investigated these applications, to assess the technical as well as financial benefits for photovoltaics in utility scale applications. Other novel configurations of grid-tied PV

\footnotetext{
${ }^{1}$ While this book was going to press in November 2002, BP Solar suddenly announced the closure of its two thin-film manufacturing efforts in the United States (a-Si in Virginia and CdTe in California) in order to focus more resources on its multicrystalline Si wafer PV production. This was a great disappointment to all those who worked so hard to establish these thin-film technologies and facilities, which were among the most advanced thin-film PV products in the world.
} 
systems were evaluated as so-called "demand side management" options where the onsite distributed photovoltaics is used to reduce demand rather than increase supply [47]. Although American utilities lost interest in PV in the late 90s due to deregulation, gridconnected applications in Europe and Japan began to grow rapidly, primarily owing to strong government support. Both small- and large-scale grid connected PV installations are blossoming in these countries [48, 49].

Yet another important development in the application of PV in the late 1990s, was building integrated PV (BIPV [50]), where PV cells are incorporated into a standard building product, such as a window or a roof shingle, or into an architectural feature like an exterior sun awning or semitransparent skylight. In this way, the cost of the PV is partially offset by the cost of the building materials, which would have been required anyway, so the incremental cost of the photovoltaics is much lower. BIPV is discussed in Chapter 22. The success of grid-connected residential or BIPV commercial applications has been possible because several countries led by Germany have established high rates to pay for the PV electricity produced by solar installations in private houses. In this scheme, the installation owner receives $\$ 0.5 / \mathrm{kWh}$ for the electricity they feed into the public electric grid (as of 2001). But the owner buys the electricity consumed in their own house at the normal cost of $\sim \$ 0.1 / \mathrm{kWh}$ from the grid. Additionally, German banks provided generous loans for purchasing the installation. Similar concepts are used in Spain, the Netherlands, and other countries in Europe. But, the success has been still bigger in Japan where homebuilders receive a rebate from the government for about $30 \%$ of the PV system cost. Then, their electric bill is determined by the utility using the "net metering" where the customer pays only the net difference between what they used and what they generated. Rebates and net metering are available in some, but not all, states in the USA as of 2002. Interestingly, government support of photovoltaics in Japan has been decreasing while the market for PV homes has continued showing an impressive growth rate.

\subsection{PV COSTS, MARKETS AND FORECASTS}

In the first 20 years of PV research, from the mid 1960s to the mid 1980s, the main focus was to make the product more efficient so it produced more power. Impressive gains in cell and module efficiency were made. Costs also fell dramatically as solar cells moved from pilot scale to semiautomated production.

Although the important figure of merit for cost is $\$ / \mathrm{kWh}$, typically $\$ / \mathrm{W}_{\mathrm{P}}$ is often used. Modules are rated in Watts of peak power $\left(\mathrm{W}_{\mathrm{P}}\right)$. This is the power the module would deliver to a perfectly matched load when the module is illuminated with $1 \mathrm{~kW} / \mathrm{m}^{2}$ of luminous power of a certain standard spectrum while the cell temperature is fixed at $25^{\circ} \mathrm{C}$. (By the way, these "standard test conditions" or STC rarely occur in real outdoor applications! See Chapter 16 for a complete discussion of testing conditions and Chapter 20 for real outdoor conditions.).

Figure 1.5 shows costs $\left(\$ / \mathrm{W}_{\mathrm{P}}\right)$ and production measured in $\mathrm{MW}_{\mathrm{P}}$ over the commercial history of photovoltaics. Up until about year 2000, these values represent mostly c-Si solar cell technology. These two curves are typical of most new technologies. Initially, prices are high since volume production is low, so development and start-up 


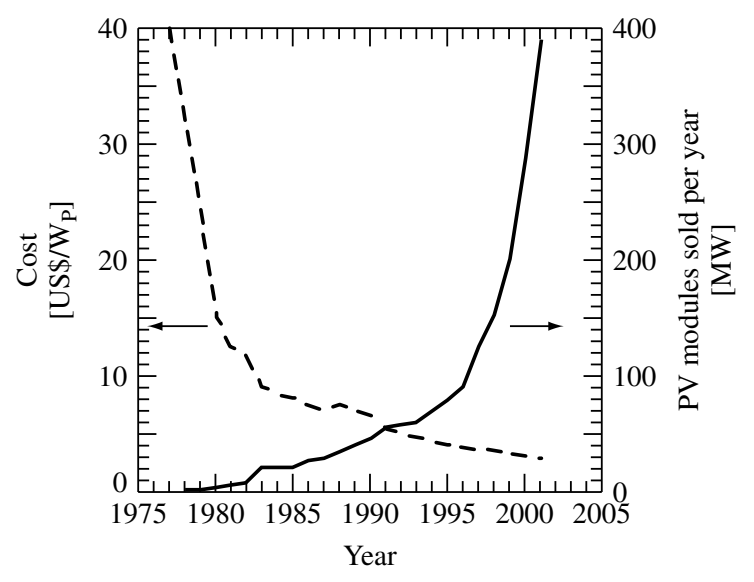

Figure 1.5 Historical trends of cost per Watt for solar cells and volume of production. Data from various sources. Beware: these costs are for PV modules not completed systems, which typically increase by a factor of 2 to 3

costs are spread over the relatively few units sold. The high price excludes most buyers except unique niche applications (i.e. remote telecommunications transmitters, where the unique properties of photovoltaics makes it the most appropriate source of electricity) government-sponsored programs (i.e. satellites, weather monitoring stations, military outposts and also human development programs in remote areas including water pumping), and curious wealthy pioneers (i.e. private homes in the mountains for environmentally concerned millionaires). As volume production increases, costs fall as economies of scale take over. The technology is now within economic reach of wider markets and demand grows rapidly as people with moderate incomes can afford the product. Eventually, the decrease in price slows, and it becomes harder to improve the cost and performance of a given product. But each small decrease in cost opens up larger markets and applications. Once a certain price is reached, a massive new market will open up with ample opportunity for investors to finance new manufacturing capacity.

This relation between cumulative production of PV modules in $\mathrm{MW}_{\mathrm{P}}(M)$ and price in $\$ / \mathrm{W}_{\mathrm{P}}(p)$ can be described by an experience curve, which is characterized by a parameter $E$ called the experience exponent $[51,52]$ or

$$
\frac{p(t)}{p_{0}}=\left[\frac{M(t)}{M_{0}}\right]^{-E}
$$

where $M_{0}$ and $p_{0}$ are the cumulative market and the price at an arbitrary initial time $t=0$ (that we can take at the beginning of the early commercialization). The experience curve for photovoltaics is shown in Figure 1.6 where lowest price per $\mathrm{W}_{\mathrm{P}}$ for a given year is plotted against the cumulative module production up to that year. When graphed as a $\log -\log$ plot, it is the slope that is of significance since it defines the experience factor given as $1-2^{-E}$. This quantity indicates how much costs are reduced for every doubling of cumulative production. Figure 1.6 presents an exponent $E=0.30$ which gives an experience factor of 0.19 . Thus, prices have fallen $19 \%$ for every doubling in 
cumulative production over the past 30 years. If the trend continues, the price of $\$ 1 / \mathrm{W}_{\mathrm{P}}$ will be reached when the cumulative production reaches $10^{5} \mathrm{MW}_{\mathrm{P}}$.

It should be said that while the annual growth in sales of photovoltaics is quite spectacular, averaging 33\% per year from 1995 to 2000, the experience factor of 0.19 is rather mediocre. For example, for semiconductor memories it is about 0.32, although for wind power it is only 0.15 . PV technology has not reduced prices very effectively. This supports the idea that $R \& D$ must be supported to look for innovative options able to reduce prices beyond the safe path of the experience curve (additional argument for myth 4).

When this cumulative market will be reached can be determined, if we know the demand elasticity $S$. Technically, this is the logarithmic derivative of the annual market with respect to the price (changed of sign) and shows that one percent of price decrement will produce $S$ percent of market increase. This parameter allows us to determine when in the future a certain level of price is reached [52].

Based on this, the installed PV power is given in Figure 1.7 for reasonable values of the demand elasticity. We can observe a fast initial growth, followed by a period of moderate growth. This second period is determined by the investment that society is willing to invest in this expensive energy technology. Extreme curves of the shaded area correspond to the expenditure for photovoltaics of the case that $0.05 \%$ (lower curve) and the $0.2 \%$ (upper curve) of the GDP of the industrialized countries is invested every year in PV electricity. As a reference, about $0.3 \%$ of the industrialized countries GNP is being given today as aid for development.

In 1992, a study (the RIGES scenario [54]) was presented to the Rio Summit analyzing the possibility of reducing the $\mathrm{CO}_{2}$ emissions while maintaining a high economic growth rate in the developing countries. The dots represent the amount of photovoltaics to attain the RIGES requirements. In other words, the dots are the amount of installed photovoltaics required to be environmentally relevant and socially advanced. Note that

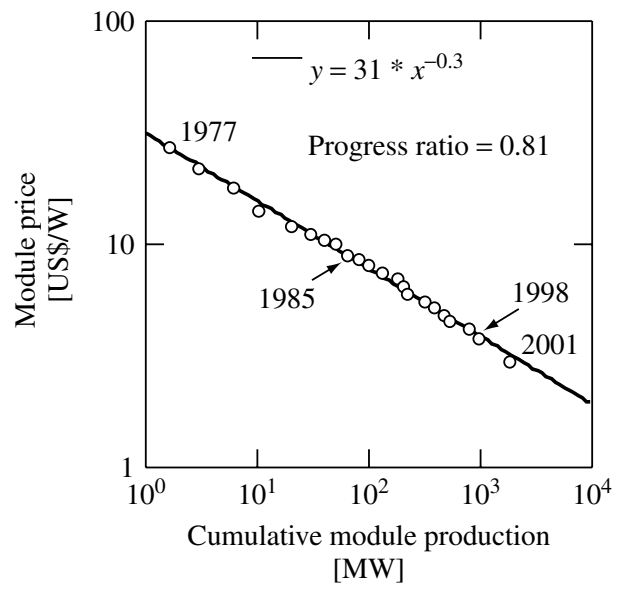

Figure 1.6 Experience curve for photovoltaics from 1976 until 1998 [53]. Straight line is fit indicating an experience factor of $1-2^{-0.3}=0.19$ 


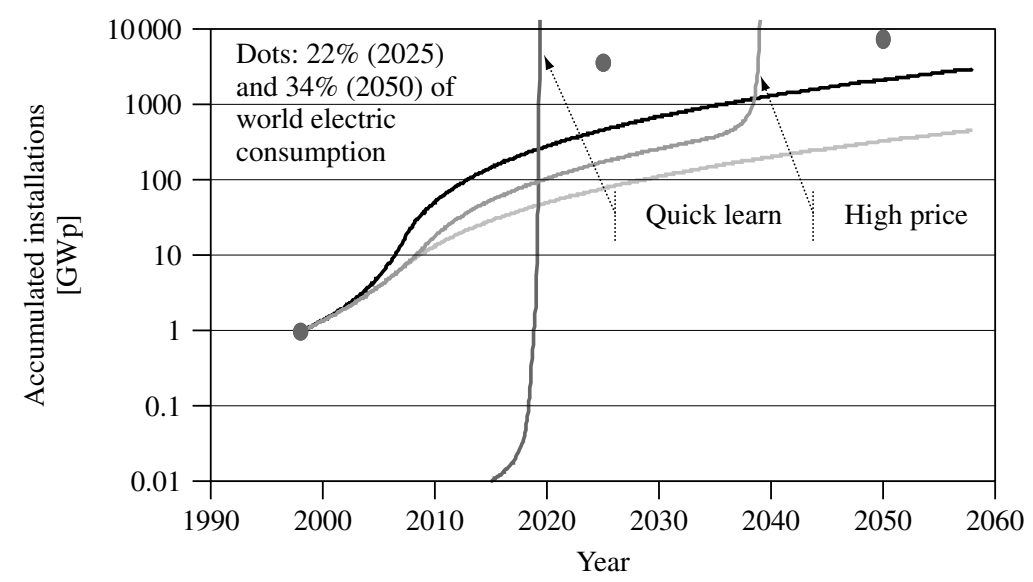

Figure 1.7 Long-term forecast of cumulative installed peak PV power. The dashed area represents the expected cumulative installed capacity for a range of assumptions associated with the demand elasticity. PV prices (not shown) will not be competitive in the period shown unless the conventional electricity doubles in price (in constant dollars). However, photovoltaics will be competitive if some innovation develops and is commercialized with a "quick learn" experience factor like that of the microelectronic memories (0.32). Dots represent the level of electricity penetration to reach environmental goals (see text)

the goal for 2050 is to produce the $34 \%$ of the total world electricity production; by no means a niche market to be produced by a cottage industry!

It is observed that with the present low experience factor, the environmental goals are not achieved. Nevertheless, this forecast predicts that the PV industry will be very large by the middle of the century.

The curve labeled high price refers to the case where conventional electricity prices are doubled. In this case, photovoltaics will reach price competitiveness with the existing electricity before the middle of the century (the almost-vertical line means photovoltaics is cheaper than conventional electricity but realistic growth will occur more slowly). Perhaps a hidden but practical conclusion of this analysis is that support to the PV industry will result in an additional element of security in the supply of electricity. Energy security is of increasing interest for the public officials as well as for citizens.

The preceding cases correspond to the situation governed by a constant experience factor. No technological breakthrough is considered. What would be the situation if a breakthrough were produced? A breakthrough technology would be characterized by a higher experience factor and should be able to reduce costs by experience faster than present PV technology. The curve labeled quick learning in Figure 1.7 shows the case of a technology with the experience factor of the microelectronic memories. Note that in very few years (after real commercialization starts) it would be able to reach competition with conventional electricity.

However, note that this success is based on reaching a certain cumulative market (in this exercise $10000 \mathrm{MW}$ ) despite the higher price of this technology at its early stage as compared to the competing PV technology. This is a commonly occurring situation and 
must be taken into account by investors. Comparison must not be made between prices of different alternatives at the same moment in time but for equal cumulated market. In other words, we must compare the price of an option today with that of its more mature competitor in some moment of the past and we must also consider the experience factor. In other words, sometimes a product that at a given moment is more expensive than its competition can become cheaper sooner because it bears internally the seed for lower cost and comparable performance. But, of course, not every more-expensive novel product bears this seed. This is the risky nature of entrepreneurship.

We conclude, and this is our position concerning the controversy pointed out in myth 4, that basic R\&D in photovoltaics must be looking for breakthroughs if we want photovoltaics to fulfill the goals that society requests. At the same time, support to the market will help create a sizeable industry that will be able to commercialize breakthroughs worldwide. In any case we are not talking of a cottage industry. The PV industry has the potential of becoming a major electricity supplier in the twenty-first century and to constitute a powerful industry able to abate environmental stresses, to facilitate the human development of the poorest, and to constitute an element of safety in our electric supply.

\subsection{WHAT ARE THE GOALS OF TODAY'S PV RESEARCH AND MANUFACTURING?}

Chapters 5 to 15 in this book focus on individual technologies and will give specific examples of where the research and manufacturing effort is concentrating to reduce costs and improve performance. But several trends are common to all. These are listed in Table 1.3.

Since the overall goal is to produce a low cost PV system, we need more than low-cost-efficient solar cells, we need a low cost efficient system including mounting hardware, power conditioning electronics, fuses, cables, storage, tracking, and so on. Less research and development has gone into these areas than into PV solar cells and modules.

Table 1.3 Goals of current solar cell research and manufacturing

- Use less semiconductor material by making thinner cells or

- Use less expensive semiconductor materials. These tend to be less pure and less perfect.

- Improve solar cell performance with less expensive, less perfect semiconductors

- Even with this poorer material keep a high production yield, that is, reduce the number of cells or modules rejected by the quality control.

- Increase material utilization by reducing waste in semiconductor and cell fabrication

- Increase solar cell flux on the solar cells by using concentrators without increasing cost or optical losses too much. In this way, less semiconductor material is used.

- Increase solar radiation utilization by absorbing more of the spectrum efficiently

- Increase speed and throughput of manufacturing processes

- Simplify processing steps (this reduces fabrication costs and increases the yield) and reduce equipment costs

- Reduce costs and improve reliability of BOS (auxiliary elements). 


\subsection{GLOBAL TRENDS IN PERFORMANCE AND APPLICATIONS}

Figure 1.8 shows the trends in efficiency achieved over the past 20 years for all the major PV technologies. These results are for small area "champion cells", the one-of-a-kind result that establishes the potential of a given material system and device technology. The highest efficiency is for the most expensive and complex devices, based on III-V technologies like GaAs and GaInP, consisting of multiple devices with different optical and electrical properties, grown on top of each other. They are discussed in Chapter 9. These multijunction (MJ) cells outperform other cell technologies for three reasons. They are made from very perfect and high-purity crystalline materials, they can capture either a wider range of the solar spectrum or the same range more efficiently than other devices, and they are operated with high concentration factors, using lenses, which increases the efficiency for reasons discussed in Chapter 3. Not surprisingly, they are also extremely expensive.

The workhorse of the PV industry is still $\mathrm{Si}$ as discussed in Chapters 5, 6, and 7. Si wafers in the form of either single crystal Si or multicrystalline (also called polycrystalline) $\mathrm{Si}$ accounts for $90 \%$ of the PV market. Although champion single crystal (c-Si) and multicrystalline $\mathrm{Si}$ (multi-Si) cells have been recorded with $25 \%$ and $20 \%$ efficiency, respectively (both made at UNSW in Australia), the difference in module performance between the two Si-wafer technologies is much smaller. They have typically $14 \%$ and $12 \%$ efficiency in commercial modules, respectively. Despite three decades of research and manufacturing, clever scientists and engineers are still finding ways to improve the performance of Si-wafer photovoltaics. They are also finding ways of reducing the cost.

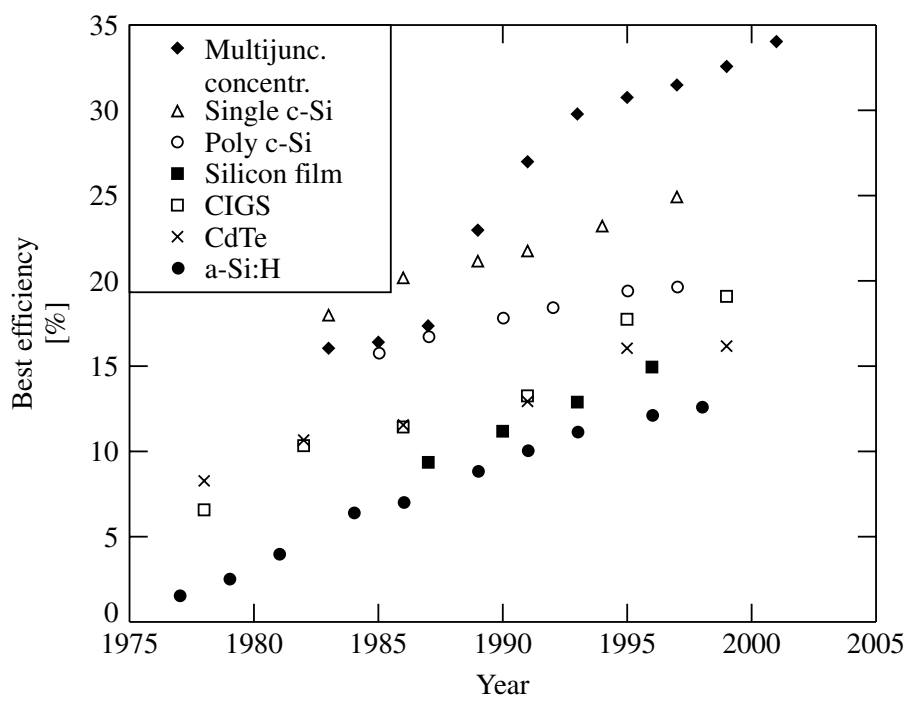

Figure 1.8 Best small area $\left(0.5-5 \mathrm{~cm}^{2}\right)$ efficiency for various cell technologies measured under standard laboratory test conditions. MJ concentrators are double junctions before 1995, and triple junctions after. a-Si represents stabilized efficiency after extended light soaking and are MJ after 1990 (see Chapter 12) 
Among these attempts are the developments of silicon sheets, which avoid the wafering of bulky Si ingots, a very expensive and wasteful process. Ribbon sheets have already reached a noticeable fraction of the market with two companies: RWE in Germany/USA (leading) and Evergreen Solar in the USA.

Continuing down the efficiency axis we come to the three leading thin-film PV contenders, $\mathrm{Cu}(\mathrm{InGa}) \mathrm{Se}_{2}$ (CIGS) (Chapter 13), CdTe (Chapter 14), and a-Si (Chapter 12), in that order. The main motivation for interest in thin-film photovoltaics has always been the possibility of lower cost, not higher performance. Their champion cell performance has always been a factor of about 2 lower than Si-wafer technologies until 2000, when $\mathrm{Cu}(\mathrm{InGa}) \mathrm{Se}_{2}$ cells with efficiencies of $19 \%$ were reported, putting them in potentially close competition with multi-Si, although there are vast differences in the manufacturing experience base between $\mathrm{Cu}\left(\mathrm{InGa}_{2} \mathrm{Se}_{2}\right.$ (no base) and multi-Si (large base). The benefits and challenges of thin-film PV technologies are discussed in detail in Section 1.9. Finally, we note that the category of "Si film" solar cells in Figure 1.8 is a special case of solar cells developed entirely by one company (Astropower in the USA), in which they are attempting to achieve the high performance of polycrystalline $\mathrm{Si}$ with the low-cost approach of thin films. More information about thin-film Si technology is given in Chapter 8.

The results in Figure 1.8 clearly show that there are many promising technologies in terms of their possibility of achieving rather high efficiency. But the reality is that, as seen in Figure 1.9, almost $90 \%$ of the world's PV power modules are either single c-Si or multi c-Si. The evolution shows a trend away from c-Si towards the multicrystalline-Si technology with the market share of Si sheet also increasing. About $10 \%$ of worldwide PV sales are a-Si/a-Si or a-Si/a-SiGe multijunctions and the remaining $<1 \%$ is $\mathrm{Cu}(\mathrm{InGa}) \mathrm{Se}_{2}$, $\mathrm{CdTe}$, and concentrators. The multijunction concentrators based on GaInP/GaAs cells have yet to find commercial application on Earth but nonconcentrating GaInP/GaAs cells are commonly used for space missions where their high efficiency is more important than their high cost. High performance GaInP-based technology is discussed in Chapter 9 and PV space power is described in Chapter 10.

Who is making all the PV modules? Figure 1.10 shows the breakdown by the three major geographic regions of Europe, Japan, and the United States. Note that this is a logarithmic scale, indicating very steady growth for the past decade of 20 to $30 \%$. Production in 2001 was actually 36\% higher than in 2000. The USA has had steady growth and led the world in photovoltaics between 1992 and 1998 when Europe and Japan

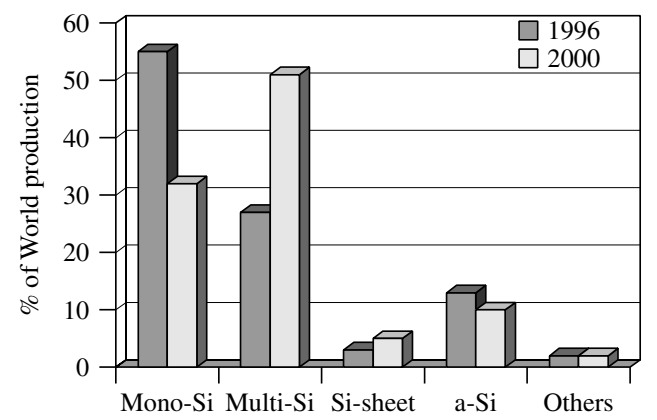

Figure 1.9 Distribution of the PV market by technologies 


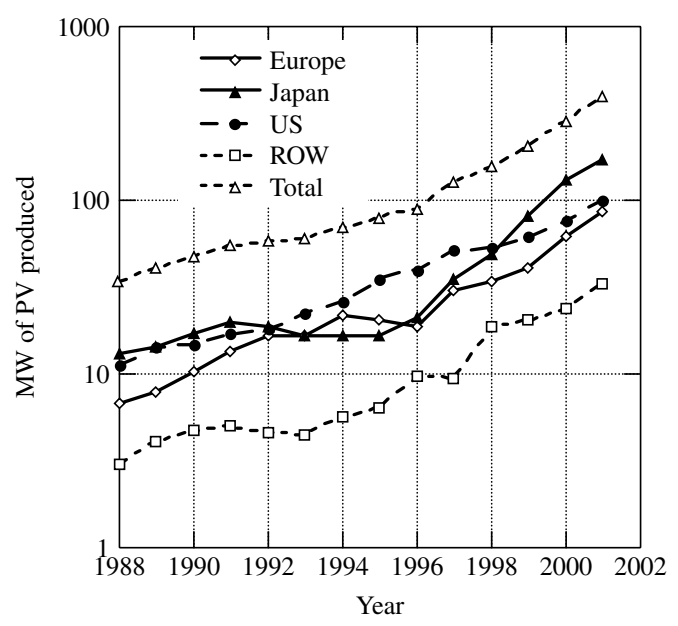

Figure 1.10 World production of PV modules

had static manufacturing growth. Then in 1998, progressive and supportive government policies in many European countries and in Japan resulted in a substantial increase in production. These policies were driven partly by a strong commitment to $\mathrm{CO}_{2}$ reduction as proscribed by the Kyoto Protocol. European production is dominated by Spain closely followed by Germany, and to a lesser extent France, Italy, and The Netherlands. Note that these figures do not indicate the final residence of the PV module, only its place of birth. For example, a large fraction of PV modules made in the US $(\sim 70 \%)$ and Spain $(\sim 80 \%)$ are in fact exported.

We present in Figure 1.11 the top ten PV manufacturers in 2001 [55]. The list is headed by the Japanese electronics company, Sharp, followed in the third position

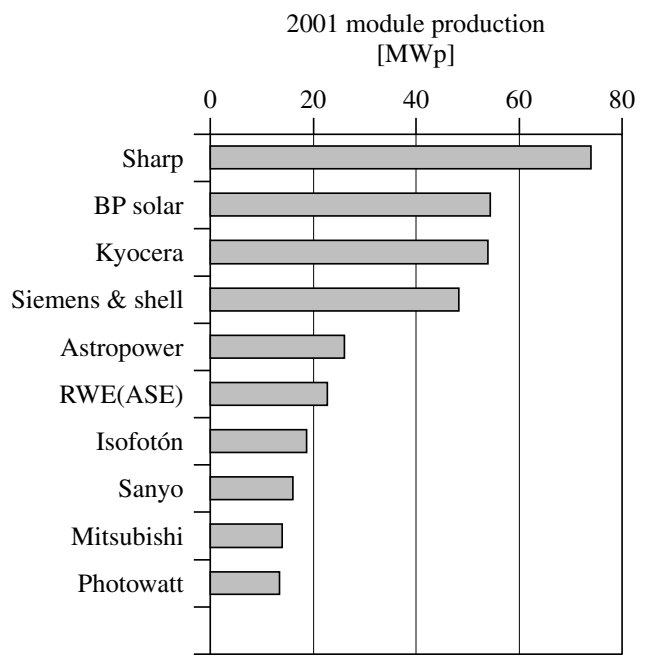

Figure 1.11 The top ten PV cell manufacturers in 2001 
by Kyocera, another Japanese company. The second place is held by the UK-based oil multinational BP Solar with c-Si and multi-Si plants in United States, Spain, Australia, and India. BP Solar also had two thin-film technologies in commercialization in the United States, namely a-Si and CdTe, (see footnote in Section 1.4). The biggest PV manufacturer in the USA today is Shell Solar (formerly Siemens Solar) but is held by European capital. As of this writing, of all the companies in Figure 1.11, only Astropower (US), Isofoton (Spanish), and Photowatt (French but held by Canadian investors) focus their business exclusively on photovoltaics. The others are either divisions or subsidiaries of large companies with diverse manufacturing interests.

Figure 1.3 showed the worldwide trend for various applications. Growth has been driven by distributed, grid-connected PV applications since 1996, mostly in Europe and Japan, as discussed above. There is steady growth in use of photovoltaics for diesel hybrid and communication. These are off-grid applications, typically in remote locations. Previously, operating a diesel generator $24 \mathrm{~h}$ a day or replacing large battery packs was the only alternative. PV diesel hybrids can be cost-effective in these cases [56].

Note that Figure 1.3 shows that large-scale, centralized solar power plants are almost nonexistent. These huge "solar electric farms" were envisioned in the early days of photovoltaics to be built in sunny arid deserts, where land was essentially worthless for other uses (note, that photovoltaics operates without water in contrast to conventional thermal power plants). These huge facilities would replace conventional power plants, at least for daytime power. The world's largest centralized PV power plant to date was installed in central California between 1984 and 1985. The operation and performance over several years was reported [57], including operation and maintenance costs [58]. After several years of operation, the installation was disassembled and the modules were sold individually on the market. Presently, the largest centralized PV power plant is $3 \mathrm{MW}$ in Serre, Italy [59]. There have been several other large-scale PV installations, and their installation techniques, labor, and operation costs have been well documented. In particular, the 0.4 MW a-Si plant in California, USA [60] and the 0.48 MW concentration plant [61] in Tenerife, Spain are notable because they do not use the ubiquitous unconcentrated c-Si technology.

\subsection{CRYSTALLINE SILICON PROGRESS AND CHALLENGES}

Figure 1.9 showed that $\mathrm{c}-\mathrm{Si}$, as either single or multicrystalline wafers or ribbons, was responsible for almost $90 \%$ of worldwide PV production in 2001. How did its dominance occur?

First, there was a tremendous worldwide scientific and technical infrastructure for Si starting in the 1960s. Huge government and industrial investments were made in programs for understanding the chemical and electronic properties of $\mathrm{Si}$, how to grow it with the required purity and crystalline structure, and to create the equipment needed to perform all the processing steps. The motivation was not just idle scientific curiosity, but rather the competitive drive to manufacture increasingly complex integrated circuit chips, which created first the analog then the digital electronic revolutions leading to our current information, entertainment, and telecommunications industries. The promise of wealth and market dominance led public and private organizations to unlock many 
secrets of Si technology. The silicon band gap, of $1.1 \mathrm{eV}$, is almost optimum to make a good solar converter, as explained in Chapters 3 and 4. The PV industry could utilize the preceding gains for their own application without having to re-create this scientific and technological infrastructure. In addition, $\mathrm{Si}$ is one of the most abundant minerals in the Earth's crust. Thus, there was no physical limitation to providing a huge fraction of the Earth's electricity needs with the known Si reserves.

However, for mechanical reasons (it is brittle), silicon requires relatively thick cells, with a typical wafer thickness of about $300 \mu \mathrm{m}$. Therefore, some of the electrons pumped by the photons to the conduction band have to travel large distances, on the order of the thickness, to be extracted by the front face through the selective contact to this band (the pn junction). Consequently, a good material with high chemical purity and structural perfection is required to fight the natural tendency of the conduction-band electrons to return to the valence band. This loss process is called recombination. To avoid this loss, the electrons must be highly mobile, as they are in perfect silicon. Impurities and imperfections must be avoided as they can absorb the extra energy of the conductionband electrons and convert it into heat, thus eliminating the free electron from traveling through the circuit by immediately restoring it to the valence band energy. Producing heat, which is desirable in solar thermal panels, where this heat is transferred to a fluid, is undesirable in PV modules, where we try to recover the solar energy as electricity, of much higher value.

Metallurgical Grade (MG) Silicon is obtained by reduction of quartz with coke in an arc furnace. Then it is strongly purified by a method developed by and named after the Siemens Company consisting of the fractional distillation of chlorosilanes, which are obtained from the reaction of $\mathrm{HCl}$ with $\mathrm{Si}$. Finally, silanes are reduced with hydrogen at high temperatures to produce hyperpure silicon, usually called Semiconductor Grade (SG) Silicon or just polysilicon (it is called polysilicon because it has many grains of crystalline $\mathrm{Si}$, typically of about $1 \mathrm{~mm}$ ).

The polysilicon now has the desired chemical purity (unwanted impurities below the parts per billion (ppb) level, or less than one impurity atom for every $10^{12} \mathrm{Si}$ atoms, for some impurity atoms), but its structural quality is deficient. The structural quality is improved by melting the polysilicon $\left(>1400^{\circ} \mathrm{C}\right)$ and "freezing" or allowing it to solidify very slowly around a rotating crystalline seed, usually by the Czochralski $(\mathrm{Cz})$ method. In this way, a cylindrical single crystalline ingot is obtained of about $25 \mathrm{~cm}$ diameter and of $100 \mathrm{~cm}$ length. In this step, a very small number of atoms of boron are introduced in the melt to allow the appropriate metallic contacts deposited later to be selective to the valence-band electrons. This forms the $p$-type side of the $p n$ junction.

The ingot is now cut in wafers with a saw. For this a very long wire (up to $500 \mathrm{Km}$ ) is wound many times on rotating drums cuts with slurry the silicon ingot into wafers. However, the process is slow and about half of the silicon is lost in the sawdust. The challenge here is to cut the wafers thinner so as to make more profit from the silicon. Wafers of $150 \mu \mathrm{m}$ instead of the standard $300 \mu \mathrm{m}$ are used in some companies. The techniques and challenges related to crystal growth and sawing are described in detail in Chapter 6.

The wafer is now etched slightly to remove the saw damage and to condition (texture) the surface for better light absorption. Then the conduction-band selective contacts 
are made by introducing atoms of phosphorus to one surface of the wafer, making it the $n$-type partner in the $p n$ junction. This is done by locating the wafers in a phosphorus rich atmosphere at high temperature so that these atoms penetrate slightly $(\sim 0.2 \mu \mathrm{m})$ into the silicon wafer.

Then metallic grids are printed on the boron and phosphorus-doped zones (some tricks, sometimes proprietary, are used to separate boron- and phosphorus-doped regions properly) and the solar cell is thus finished. The grids make it easier to collect the electricity without resistance losses and are commonly applied with low cost screenprinting methods. But a solar cell is brittle and produces low voltage (about $0.5 \mathrm{~V}$ ) so that some 36 cells (or multiples of this number) are interconnected with tinned copper ribbons and encapsulated in a sandwich formed of a sheet of tempered glass, an embedding polymer that surrounds the solar cells, and a back sealing plastic layer. The reason for multiples of 36 cells is so that their output voltage $\sim 15 \mathrm{~V}$ will be compatible with most DC battery charging applications.

The lowest (publicly offered) module selling prices in 2002 were about $\$ 3 / \mathrm{W}_{\mathrm{P}}$. The breakdown of costs, as given in Chapter 6 are presented in Figure 1.12. The wafer itself represents about $65 \%$ of the module cost, approximately equally divided between purification, crystallization, and sawing. This hyperpure silicon is found today as a scrap or waste product from the microelectronics industry at a price of $\sim \$ 50 / \mathrm{kg}$. The increase of the PV market in the 1990s has nearly exhausted this market. Additional supplies are coming from the former Soviet Union, whose microelectronic industry has disappeared due to western competition. The Siemens method is considered ultimately too expensive for photovoltaics, but the purity it provides seems necessary for the fabrication of solar cells. Attempts in the 1980s to fabricate a low-cost solar silicon (SolSil) did not succeed due in part to the scarce interest generated by the small markets of the time. Today, new attempts are being made. These might include purification in the MG silicon production steps and in the crystal growth steps avoiding the expensive chlorination procedure and using the molten step of the crystal growth for further purification, or alternately, reducing the chlorosilanes in the molten phase prior to the crystal growth. It is not clear whether they can achieve the needed purity level. Even if feasible it is uncertain whether such wafers would be less expensive than the standard Siemens process or some simplified versions of it. There are fears that a shortage of hyperpure polycrystalline silicon availability might seriously hinder the growth in cell production demanded by the market. Chapter 5

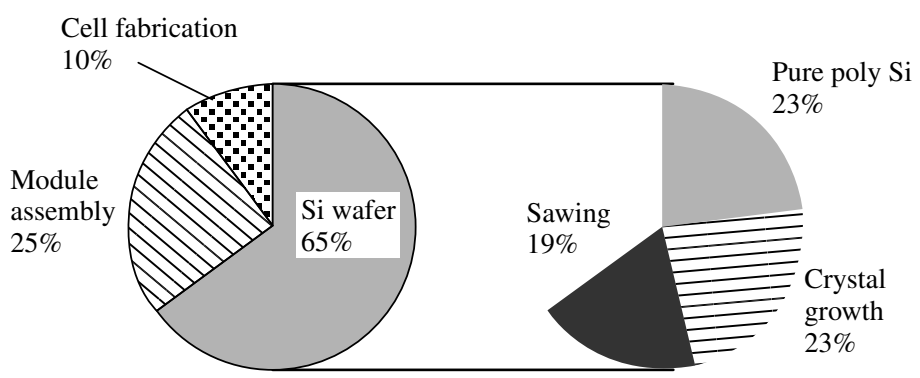

Figure 1.12 Breakdown of costs in the fabrication of a Si-wafer-based PV module. The right side presents the wafer costs 
describes in detail the problems and challenges associated with silicon production and purification.

An important advance in solar cell fabrication was the demonstration that solar cells with high efficiency can be fabricated from wafers containing hundreds of large-grain (1-10 mm) multicrystals, called multicrystalline (multi-Si) or polycrystalline (poly-Si), although this later term is less favored because it may cause confusion with the feedstock (polysilicon). The multi-Si growth procedure is much faster and the wafer is cheaper. The loss of efficiency of a few percent (absolute) caused by the random orientation of crystalline grains in a multi-Si wafer compared to a single c-Si wafer is balanced by the lower cost so that the price per watt peak is the same on a module basis. But the simplicity of the multi-Si wafer-growing equipment and process is producing a clear trend towards the use of the multicrystalline option as seen in Figure 1.9.

An interesting option in $\mathrm{Si}$ solar cell manufacturing is the growth of ribbons $[62,63]$. Ribbons do not require the expensive sawing process. However, the growth of the ribbon crystal is slower because they usually grow in the plane perpendicular to the ribbon surface, with very small area (the ribbon width times the thickness). In contrast, wafers grow in the plane of the wafer surface whose area is the wafer area. The standard ingot solidification process is a very effective purification process due to the preferential segregation of impurities to the molten silicon. However, in ribbon Si the plane of solidification moves faster (although with very small area), so the segregation is less effective. In summary, the ribbon cells are almost as good as the multicrystalline bulk-grown cells and possibly cheaper. Challenges lie in increasing the growth speed and the resulting cell efficiency.

Although the solar cell manufacturing process represents a relatively small fraction of the total cell cost, it strongly affects the overall cost in $\$ / \mathrm{W}_{\mathrm{P}}$ because it determines the cell and module efficiency. This efficiency depends on the quality of the wafer or ribbon utilized but it also greatly depends on the cell process itself.

As a matter of fact, an efficiency of $25 \%$ has been achieved for laboratory cells in a long complex process where every possible efficiency-improving detail has been implemented to produce a complicated but nearly ideal device structure. This is explained in Chapter 7. However, most factories use some variation of the wafer and cell fabrication process described above, including the screen-printing process, that leads to $15 \%$ single crystal cells or $13 \%$ multicrystal cells. In modules, these efficiencies are reduced to $14 \%$ or $12 \%$, mainly due to the redefinition of area that now includes the module frame. This process is considered the best compromise between costs and performance.

The existence of the large efficiency gap between laboratory and commercial cells, together with the increasing markets, suggest that novel, high efficiency commercial cell processes will appear in the next years. Some companies (BP Solar or Sanyo, for instance) are already on this path and have different processes leading to 17 to $18 \%$ cells in production. It is worth noting, that the ribbon technology is incompatible (see Chapter 7) with the ubiquitous screen-printing processing, so that a new processing, which may not be so cheap, is required to fabricate cells with this material.

An additional factor very seriously affecting the cell cost is the production yield. In the fabrication of any semiconductor device, not every unit introduced into the production 
line is successfully completed. In good single crystal Si cells, the manufacturing yield is 95\%. Many supposedly cheap technologies find their Achilles' heel in the low yield.

Finally, the module fabrication requires interconnecting and encapsulating the cells. These steps also have room for some cost reduction. The use of cheaper materials may help somewhat, as well as better automation, better module interconnection, and integration designs.

\subsection{THIN FILM PROGRESS AND CHALLENGES}

One might ask "why develop a totally different semiconductor technology for photovoltaics when Si is so well established?". The simplest answer is "to achieve lower cost and improved manufacturability at larger scales than could be envisioned for Si waferbased modules." In fact, we have already defended our belief that Si technology, very important in the next decades, will not be able to reach the ultimate goals required for mass worldwide penetration of photovoltaics (Section 1.5). What were the disadvantages of $\mathrm{c}$-Si that led to the early investigation and eventual commercialization of alternatives? It was recognized early in the development of photovoltaics that Si crystals were expensive and slow to grow. It was also recognized that of all the viable semiconductors, Si would require the greatest thickness to absorb sunlight, due to its unique optical properties. $\mathrm{Si}$ is the most weakly absorbing semiconductor used for solar cells because it has an indirect band gap while most of the other semiconductors have a direct band gap (see Chapter 3 for a more complete explanation of direct and indirect band gaps). Therefore, at least ten times more crystalline $\mathrm{Si}$ is needed to absorb a given fraction of sunlight compared to other semiconductors like $\mathrm{GaAs}, \mathrm{CdTe}, \mathrm{Cu}(\mathrm{InGa}) \mathrm{Se}_{2}$, and even other forms of $\mathrm{Si}$ such as a-Si. Thicker semiconductor material means higher material volume but also a higher quality material because of the longer paths that the high-energy electrons excited by the photons must travel before they are delivered to the external circuit to produce useful work. All this leads, as seen before, to high material cost. In addition, we mention that, presently, much of the Si-PV industry relies on buying scrap material from the electronics industry. As photovoltaics' demand grows, the supply of scrap material might become insufficient (see Chapter 5).

It was recognized almost as early as c-Si PV cells were developed in the 1950s that other semiconductors could make good solar cells. Most of them exist in a form called thin films. When they are fabricated into useful devices, they are so thin that they must be deposited on a foreign material called a substrate for mechanical support like a layer of paint on a piece of wood or the reflective metal coating on glass to form a mirror. A framework for analyzing the material properties, device structures, and manufacturing issues unique to thin-film solar cells (TFSC) was developed [64] since they differ considerably from Si wafers. Throughout the 1970s, progress in $\mathrm{Cu}_{2} \mathrm{~S} / \mathrm{CdS}$ solar cells led to the development of new theories to explain the device performance, new methods of materials processing, and new concepts in semiconductor device manufacturing [65, 66]. Between 1981 and 82, four thin-film technologies demonstrated the ability to cross the magical $10 \%$ efficiency barrier, thus becoming candidates for serious consideration: $\mathrm{Cu}_{2} \mathrm{~S} / \mathrm{CdS}$ [67], a-Si [68], $\mathrm{CuInSe}{ }_{2} / \mathrm{CdS}$ [69], and $\mathrm{CdTe} / \mathrm{CdS}$ [70]. (It is an inexplicable fact in this business that $10 \%$ efficiency seems to suddenly confer respectability and status to any PV technology.) Of these four TFSC technologies, $\mathrm{Cu}_{2} \mathrm{~S} / \mathrm{CdS}$ would soon be 
rejected for commercialization due to fundamental and fatal stability problems related to electrochemical decomposition [71]. In contrast, a-Si has a minor stability problem that is not catastrophic and has not been a major barrier to further development and production as discussed in Chapter 12. No fundamental stability problem has been found with $\mathrm{Cu}(\mathrm{InGa}) \mathrm{Se}_{2}$ and $\mathrm{CdTe}$ modules. Consequently, significant industrial and governmentsponsored research and development resources have been directed worldwide at TFSC technology. This has led to steady progress in champion cell efficiencies as seen in Figure 1.8.

The main advantage of TFSC is that they will eventually have lower costs than c-Si-wafer PV technology when they are produced in sufficiently large volumes to offset the initial capital investment. The lower costs of TFSC derive from the following characteristics: they are typically 100 times thinner than $\mathrm{Si}$ wafers $(\sim 1-3 \mu \mathrm{m}$ for all the semiconductor layers) deposited onto relatively low-cost substrates such as glass, metal foils, and plastics; they are deposited continuously over large areas at much lower temperature (200 to $500^{\circ} \mathrm{C}$ vs $\sim 1400^{\circ} \mathrm{C}$ for $\mathrm{c}-\mathrm{Si}$ ); they can tolerate higher impurities (thus needing less expensive purification of raw materials); and they are easily integrated into a monolithic interconnected module. For a reference, the semiconductors in typical TFSC are 10 times thinner than a human hair. TFSC are either polycrystalline with small $\sim 1 \mu \mathrm{m}$ sized grains such as $\mathrm{Cu}(\mathrm{InGa}) \mathrm{Se}_{2}$ or $\mathrm{CdTe}$, or else amorphous like a-Si. This is a consequence of being deposited at temperatures too low to allow perfect crystalline bond formation. TFSCs typically consist of 5 to 10 different layers whose functions include reducing resistance, forming the $p n$ junction, reducing reflection losses, and providing a robust layer for contacting and interconnection between cells. Some of the layers are only $\sim 20$ atoms thick $(10 \mathrm{~nm})$, yet they may be a meter wide! This requires excellent process control. The manufacturing process is designed such that they are deposited sequentially on moving substrates as in a continuous process line. This minimizes handling and facilitates automation, including laser scribing, to isolate and interconnect individual cells on the module, called monolithic integration.

With all the advantages of TFSCs, why does c-Si or multi-Si still dominate $90 \%$ of the world market? This brings us to the disadvantages of TFSC: they have lower efficiencies (so far), and they have a much less-developed knowledge and technology base compared to c-Si. Consequently, under-capitalized companies have had to struggle to develop not only an understanding of the materials and devices but also the equipment and processing to manufacture them. The thin-film PV industry has had to develop the technologies all by itself with considerably less financial resources than the Si industry had. They were not able to adopt a mature technology like the Si PV community did from the Si electronics industry.

What are the strengths and remaining challenges for the TFSC industry? We will review the salient characteristics of the three leaders: a-Si, $\mathrm{Cu}(\mathrm{InGa}) \mathrm{Se}_{2} / \mathrm{CdS}$, and $\mathrm{CdTe} / \mathrm{CdS}$.

Amorphous $\mathrm{Si}$ (Chapter 12) is deposited from hydride gases such as $\mathrm{SiH}_{4}$ using plasma to decompose the gas. This is called plasma-enhanced CVD (PECVD) and allows for large areas to be coated rather uniformly and with excellent control. However, the utilization of gases is only around 10 to $30 \%$, meaning much of the source material is 
wasted. The material has 1 to $10 \%$ hydrogen bonded to the $\mathrm{Si}$, and is often designated as $a-S i: H$. The $\mathrm{H}$ atoms passivate a large number of the defects resulting from the incomplete bonding of the Si atoms. The atomic structure has no long-range order like all other crystalline or polycrystalline materials. This can be an advantage. Films are typically deposited between 150 to $300^{\circ} \mathrm{C}$, the lowest temperature of any of the TFSC materials, allowing the use of lower-cost, low-temperature substrates. a-Si solar cells are deposited on glass, stainless steel foil, or plastic. The last two substrates are flexible allowing for "roll-to-roll" manufacturing where all the layers are deposited as the roll moves through their process zone. The $p n$ junction is formed by doping the thin contact layers as they grow with dopant gases containing the boron or phosphorous atoms. All practical aSi modules contain multiple junction devices where two or three junctions are grown on top of each other. This allows for more efficient utilization of the sunlight. The total thickness, including multiple junctions and all the contact layers, is less than $1 \mu \mathrm{m}$ excluding the substrate. The highest reported efficiency was $15 \%$ for a triple junction, which degraded to about $13 \%$ before stabilizing. While a-Si TFSCs cells may have slightly poorer performance compared to other TFSCs when tested under laboratory conditions (Figure 1.8), they have a unique feature that improves their relative performance outside in real conditions; namely, their efficiency is temperature-independent while for all other PV technologies, c-Si or thin-film, the efficiency decreases as the module heats up as in real outdoor conditions. This can result in those other modules losing 2 to $4 \%$ (absolute) of their rated output in the summer time and helps a-Si look more favorable. The three major challenges for a-Si technology are: 1) to improve the efficiency from today's 6 to $8 \%$ up to 10 to $12 \%$; 2) minimize or eliminate the self-limited degradation which reduces efficiency by 2 to $3 \%$ (absolute); and 3) to increase the deposition rate of the layers and the utilization of the gases to allow for faster, lower-cost manufacturing.

Polycrystalline layers of $\mathrm{Cu}(\mathrm{InGa}) \mathrm{Se}_{2}$ (Chapter 13) alloys have produced the highest efficiency TFSC devices and modules. TFSCs based on $\mathrm{CuInSe}_{2}$ (no Ga) achieved 12 to $15 \%$ efficiency but were limited by the low band gap. Alloying with $\mathrm{Ga}$ and/or S increases the band gap and increases the efficiency of delivering the electrons to the circuit (as discussed in Section 1.2). While many deposition methods have been explored in the laboratory, there are two different processes under commercial development. Co-evaporation forms the alloy by simultaneous evaporation of the $\mathrm{Cu}, \mathrm{In}, \mathrm{Ga}$, and $\mathrm{Se}$ from sources onto a heated substrate. The other process is called selenization, because layers of $\mathrm{Cu}$, In, and $\mathrm{Ga}$ are deposited by various means onto a substrate, then heated in the presence of $\mathrm{Se}$ from a gas such as $\mathrm{H}_{2} \mathrm{Se}$ or a Se vapor, thus contributing the fourth constituent of the alloy. Substrate temperatures typically reach 500 to $600^{\circ} \mathrm{C}$ during some stage of the growth. Substrates of Mo-coated glass are typically used although metal foils or plastic are being investigated. The $\mathrm{Cu}(\mathrm{InGa}) \mathrm{Se}_{2}$-films are $p$-type, typically 1 to $3 \mu \mathrm{m}$ thick and have crystallites or grains on the order of $1 \mu \mathrm{m}$. The $p n$ junction is formed by depositing an $n$-type layer of $\mathrm{CdS}, \mathrm{ZnO}$, or other new materials under development to replace the CdS. The highest reported cell efficiency is presently $19 \%$ and several companies have reported modules with $>10 \%$ efficiency. However, progress has been largely empirical since little fundamental understanding of the materials or devices is available. A very active area of research is developing methods to incorporate other alloys to increase the band gap even further. The three major challenges for $\mathrm{Cu}(\mathrm{InGa}) \mathrm{Se}_{2}$-related technology are: 1) to control the composition $(\mathrm{Ga}, \mathrm{S}, \mathrm{Se}$, or $\mathrm{Na})$ of the alloy through the film in a 
manufacturing environment on a moving substrate; 2) to find alternative junction partners to replace $\mathrm{CdS}$; and 3 ) to find new alloys or new deposition methods to give high performance devices with higher band gap alloys.

Polycrystalline layers of CdTe (Chapter 14) have been investigated for photovoltaics since the 1970 s. In contrast to limited process options for a-Si or $\mathrm{Cu}(\mathrm{InGa}) \mathrm{Se}_{2}$, there are over 10 methods to deposit the CdTe films that have produced CdTe solar cells exceeding $10 \%$ efficiency. Four have reached precommercialization: spray pyrolysis (SP), electrodeposition (ED), vapor deposition (VD) and close spaced sublimation (CSS). Some take place in liquid baths that are barely warm $\sim 50^{\circ} \mathrm{C}$ with $\mathrm{CdTe}$ deposition rates of $\mu \mathrm{m} / \mathrm{hr}$ (ED) while others take place in vacuum systems at temperatures high enough to soften glass $\sim 600^{\circ} \mathrm{C}$ with CdTe deposition rates of $\mu \mathrm{m} / \mathrm{min}$ (CSS). There seem to be three critical steps, however, that all efficient $\mathrm{CdTe}$ solar cells require. First, they need a post-deposition anneal in the presence of $\mathrm{Cl}$ and $\mathrm{O}_{2}$ at around $400^{\circ} \mathrm{C}$. This chemi$\mathrm{cal} /$ thermal treatment enlarges the grains, passivates the grain boundaries, and improves the electronic quality of the CdTe. Second, all CdTe layers need a surface treatment before applying a contact. This treatment can be a wet or dry process and prepares the CdTe surface by etching away unwanted oxides and leaving a Te-rich layer needed to make a low-resistance contact. Third, all high efficiency devices have a $\mathrm{Cu}$-containing material somewhere in their CdTe contact process but again, there are many ways this can be achieved. Whichever process is used to deposit the CdTe, it has been found that the entire device process is highly coupled since processing steps strongly influence previous layers. This is partially due to the CdTe grain boundaries which act like paths for interdiffusion.

The $p n$ junction is formed by first depositing an $n$-type layer of $\mathrm{CdS}$ on a transparent conductive oxide substrate followed by the CdTe layer and appropriate chemical annealing. Once the solar cell is made, the CdTe films are slightly $p$-type, typically, 2 to $8 \mu \mathrm{m}$ thick and have crystallites or grains on the order of $1 \mu \mathrm{m}$. The highest reported efficiency for a $\mathrm{CdTe} / \mathrm{CdS}$ device is presently $16 \%$. Some CdTe modules have been in outdoor fieldtesting for over five years with negligible degradation, yet other CdTe devices degrade during accelerated life testing indoors. Of the three leading TFSC technologies, CdTe may have the most challenges. The dual role of $\mathrm{Cu}$ must be resolved; it seems to be required to produce a high-efficiency device but it is also implicated in long-term stability problems. The various optimizing treatments need to be better understood so they can be simplified and transferred into production. CdTe modules may be more sensitive to atmospheric interaction $\left(\mathrm{O}_{2}, \mathrm{H}_{2} \mathrm{O}\right)$ requiring better encapsulation methods. Finally, safe and cost-effective $\mathrm{Cd}$ usage in the workplace followed by recycling at the end of the module's life need to be determined.

In fact, technically astute investors know that other factors can be more important than efficiency in selecting a technology for development. This point is made loud and clear by examining the relative performance of the three major TFSC technologies $-\mathrm{Cu}(\mathrm{InGa}) \mathrm{Se}_{2}, \mathrm{CdTe}$, and a-Si - in Figure 1.8. Note that a-Si has always had the lowest efficiency. Yet, of the three, it was a-Si that has been commercialized much earlier and more widely. It enjoys by far a much greater manufacturing capacity. As of 2001 [72], a-Si accounted for almost 9\% (34 MW) of the world PV power module production, while $\mathrm{CdTe}$ and $\mathrm{Cu}(\mathrm{InGa}) \mathrm{Se}_{2}$ power modules together accounted for less than $0.3 \%(1 \mathrm{MW})$, despite a-Si champion-cell-stabilized efficiency lagging the others by several percent. In 
reality, typical production modules of a-Si and $\mathrm{CdTe}$ are in the 7 to $8 \%$ range while $\mathrm{Cu}(\mathrm{InGa}) \mathrm{Se}_{2}$ is 9 to $10 \%$.

Why has so much capital been invested to develop a-Si technology over CdTe and $\mathrm{Cu}(\mathrm{InGa}) \mathrm{Se}_{2}$ ? A major factor was that a-Si had a stronger worldwide scientific research base, which ensured that the relation between deposition conditions and fundamental material and device properties were well characterized. In contrast, $\mathrm{CdTe}$ and $\mathrm{Cu}(\mathrm{InGa}) \mathrm{Se}_{2}$ are "orphans" because they have no real application outside of photovoltaics. Therefore, the entire knowledge base and technical infrastructure had to be developed mostly by underfunded industrial groups and a small number of university and government research labs. This shows that translating research-grade champion cell performance into production modules coming off-the-line day after day is a very challenging task. Figure 13.23 in Chapter 13 shows the time delay in translating efficiency achieved in the lab for a small area cell to a prototype large area module for the $\mathrm{Cu}(\mathrm{InGa}) \mathrm{Se}_{2}$ technology. Delays of six to eight years are typical. To conclude, the highest efficiency technology is not always going to be the best choice for a low-cost, high-yield process, at least not until much of the technical background is in place.

Recognizing that the ideal PV technology would have some of the merits of c-Si but be deposited as a thin film a few microns thick, several groups have elected to try to achieve the "best of both worlds" by developing thin films of multi-Si deposited on a substrate. This is the subject of Chapter 8. At present, the best thin-film multi-Si solar cells have the same efficiency as their $\mathrm{CuInGaSe}_{2}, \mathrm{CdTe}$, or a-Si based predecessors. This is partly because multi-Si thin-film photovoltaics also inherits some of the problems of both c-Si and thin films. In particular, passivation of grain boundaries and surfaces seems to be a major problem, yet many of the well-established passivation methods from c-Si are not applicable to multi-Si thin films.

But there are new thin-film technologies such as the dye-sensitized solar cell that operate on a very different principle than an all-solid-state solar cell, almost more like photosynthesis than photovoltaics. This fascinating new solid-liquid technology, not free of challenges either, is described in Chapter 15.

\subsection{CONCENTRATION PV SYSTEMS}

If solar cells are expensive, focusing concentrated sunlight onto fewer solar cells was considered from the earliest times as a way of reducing costs. For example, instead of a typical $100 \mathrm{~cm}^{2}$ solar cell absorbing $100 \mathrm{~cm}^{2}$ worth of sunlight, one could focus the sunlight from $100 \mathrm{~cm}^{2}$ onto a $1 \mathrm{~cm}^{2}$ of solar cell, thus reducing the solar cell cost by $99 \%$ while still utilizing the same amount of sunlight. This neglects the cost of the optical focusing elements and other special equipment needed for concentrator technology. Of course, two conditions were required. One is that the optical surface collecting the light and redirecting it to the cells had to be cheaper than the cell area it replaced and the second is that the efficiency of the cells under concentrated sunlight should not decrease substantially. The first condition is generally fulfilled if we consider only the optical surfaces. However, keeping the cells constantly in focus requires a moving structure to keep the optics pointing at the sun as it moves across the sky, which adds cost to the system. As for the cell efficiency, there are fundamental reasons (see Chapter 3) why 
it should increase with increasing luminous flux. However, in practice, ohmic resistance losses caused by the handling of large currents limits the efficiency increase. Thus, cells for concentrator applications must be carefully designed to minimize such losses and therefore they become more expensive. Yet, the small area of cells used in a concentration system, or alternatively, the large amount of electric power produced by each cell, allows for paying higher costs for the cells, and therefore allows them to incorporate many refinements in order to make such cells very efficient.

One factor that reduces the system efficiency is the loss associated with the optical hardware used to concentrate the light. Additionally, only the direct sunbeam is collected since scattered (diffuse) light is not focused. This again reduces the electric output by at least $15 \%$. However, this last reduction is compensated for in many sunny locations by the fact that the tracking system always aims the cell directly at the sun (at least for two-axis tracking systems). In contrast, with the more typical stationary modules, the output power varies like the cosine of the angle of the sun, so this is very low in morning and late afternoon, when the sun is at an oblique shallow angle relative to the module (equations describing the sun's motion and the relative illumination on a module versus time of day or time of year is given in Chapter 20). Accounting for these gains and losses, it is generally found that concentrator efficiency today tends to be somewhat higher than flat module efficiency and this tendency will increase in the future with the adoption of higher efficiency cells. It is also believed that concentrators should ultimately be cheaper than flat module silicon solar cells. However, this statement has not been confirmed in practice due to the lack of a real market, apart from a few purchases for demonstration purposes.

Actually, concentrators are appropriate for relatively large installations while the PV market has evolved so far in smaller installations such as grid-connected houses, remote homes, or telecommunication applications whose size is seldom bigger than $5 \mathrm{~kW}$. Therefore, only very few companies fabricate concentrator cells today, and their prices are very high because they have large general costs for very small production volumes. However, the situation may change. The general increase of the PV markets will probably stimulate the appearance of niches better adapted to concentrators.

The difficulty of developing concentrators must not be underestimated. Combining the requirement for high performance with the low cost is a formidable challenge. In particular, the optics must be low cost, yet permit highly accurate focussing, high optical efficiency, and equal illumination in all cells. The tracking structure must be cheap and accurate, cells must be efficient and not too expensive, and finally the cooling and current extraction must be effective and cheap. Chapter 11 deals in detail with concentrator issues.

\subsection{BALANCE OF SYSTEMS}

A photovoltaic system consists of more than PV modules composed of solar cells. In addition, it requires elements that are generically known together as "Balance Of System" (BOS). The BOS is, typically, composed of the battery, the control unit and the inverter, the mechanical support structure, the electric cabling, and protection devices such as fuses, grounding rods, and disconnect switches. We present in Figure 1.13 the cost of a PV stand-alone installation with storage, as presented in Chapter 2. 


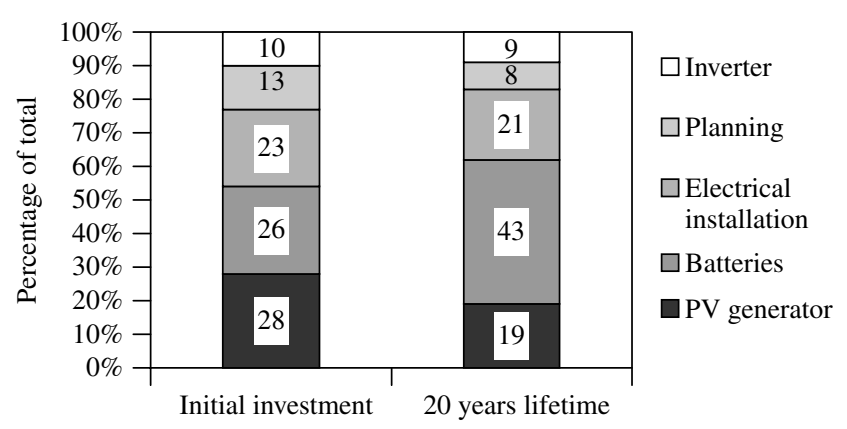

Figure 1.13 Breakdown of costs of a stand-alone PV installation with an optimum size storage. Differences in the initial investment and the life cycle investment are due to replacement of batteries during the 20 year life

We can see that in this case the PV modules represent approximately a quarter of the cost, while the cost of the batteries exceed that of the PV modules, especially when their periodic replacement over 20 years is included. This makes a very important and little appreciated point: even if we could make PV modules for free, the life cycle cost of the stand-alone system in Figure 1.13 would only be reduced by $25 \%$ ! Clearly, batteries must be examined more closely. It is fortunate that many important applications do not require battery storage and therefore are free from this major cost burden.

Batteries are in most cases the lead-acid type. While automobile batteries are optimized for providing strong current for a short period to start the car, the ideal batteries for PV systems are so-called "deep cycle" batteries that can yield a large fraction of their charge (deep discharge cycle) and must operate with high efficiency and long duration. Yet, many PV applications use standard "shallow discharge" auto batteries due to their ubiquitous availability and lower initial cost (due to massive worldwide markets and applications) to the detriment of the long-term PV system cost. Some of the modern batteries such as those based on lithium ion or lithium polymer used in laptop computers or mobile phones could be used in solar applications but they are too expensive and are not significantly better than properly managed lead-acid batteries. This is studied in detail in Chapter 18. As said before, the relatively high cost of the batteries is further increased when we consider the costs over the PV system's life cycle since the batteries have to be replaced every four to eight years due to their relatively short lifetime. Therefore, good maintenance procedures to increase the battery lifetime are important but not always applied. Alternative methods of storage exist but they will not replace lead-acid battery, at least, not in the next ten years.

The battery charge controller is essential for the long life of the battery. It is an electronic device that prevents overcharging and excessive discharging, both of which can dramatically shorten the battery's life. In large systems, equilibration of the battery charging (so that all battery cells charge equally) should also be incorporated. In hybrid systems, which combine photovoltaics and a diesel or wind generator, the control unit must connect and disconnect the different generators according to a plan. Also, loads can be categorized, so that in case of low battery charge and low PV output, some loads can be disconnected while some essential ones are maintained active. 
In many cases, battery storage is not necessary. For PV-powered water pumping, the water is pumped and stored while the sun is shining. For the grid-connected homes (one the fastest growing applications) and office buildings, the photovoltaics produces energy during the day and the grid supplies the energy during the night or on cloudy days, thus eliminating the need for batteries, simplifying system design, and reducing BOS costs. In PV-powered generating plants, the electricity is produced while the sun shines. The success of grid-connected PV applications is very sensitive to price competition with conventional electricity (even if the PV electricity is subsidized, as it occurs in Europe and Japan). Luckily the expensive batteries do not hamper this competition.

PV modules produce direct current (DC) which is suitable for directly charging batteries or powering a small number of special products. However, most appliances run on alternating current (AC). Consequently, an inverter must be used to convert the DC into AC. Inverters are widely used for many industrial applications. They are fabricated in large quantities as uninterruptible power supplies (UPS), to convert the DC electricity stored in batteries into AC electricity in the case of grid failure. They are used in hospitals and other installations where electricity failure is not tolerable. Small UPSs are often used in computers that must operate continuously. The PV inverter has an additional and important role: to vary the electrical operating point of the PV array to maintain its output at the maximum value, that is, the variable bias point at which the PV array produces highest power extraction. Changes of temperature and insolation change the voltage where maximum power extraction occurs. The electronics of the inverter typically include maximum power tracking. The inverters used in photovoltaics and the rest of the power conditioning electronics are explained in Chapter 19. Inverters have often been the source of poor reliability in early systems. Feedback to manufacturers and more robust components has greatly reduced these problems.

Because of the cost, the electronics for power conditioning is sometimes considered as a serious hindrance in the development of photovoltaics. However, we think the appearance of a significant market will reduce costs to reasonable limits. One fresh approach is to have a small inverter on the back of every module instead of a centralized inverter for the entire system. This modular approach has many advantages and is being put into production in USA [73] and Germany [74], but at present it is more expensive and will be so unless mass production reduces costs with respect to the theoretically cheaper bigger inverters.

The system-mounting structure is also important, in particular, in concentrating systems. In fact, this is the second most important cost element in concentrating PV systems, after the modules. In contrast, the power conditioning cost is comparable to many other small costs associated with the plant construction. This can be seen in Figure 1.14, where we present the breakdown of costs for a TFSC $\left(\mathrm{CuInSe}_{2}\right.$, an ancestor of today's $\left.\mathrm{Cu}(\mathrm{InGa}) \mathrm{Se}_{2}\right)$ flat module central plant and a concentrating central plant. Both sets of calculations are based on the same criteria for the two technologies involved (but based on realistic but futuristic assumptions) and presented in Chapter 21.

The plant cost is about twice the module cost: more for concentrators, less for "flat-plate" modules. Notice, that the cost of land is absolutely negligible land (provided the plant is built where land prices are low). It has to be stressed again that modules at the costs in the figure are not yet achievable. 


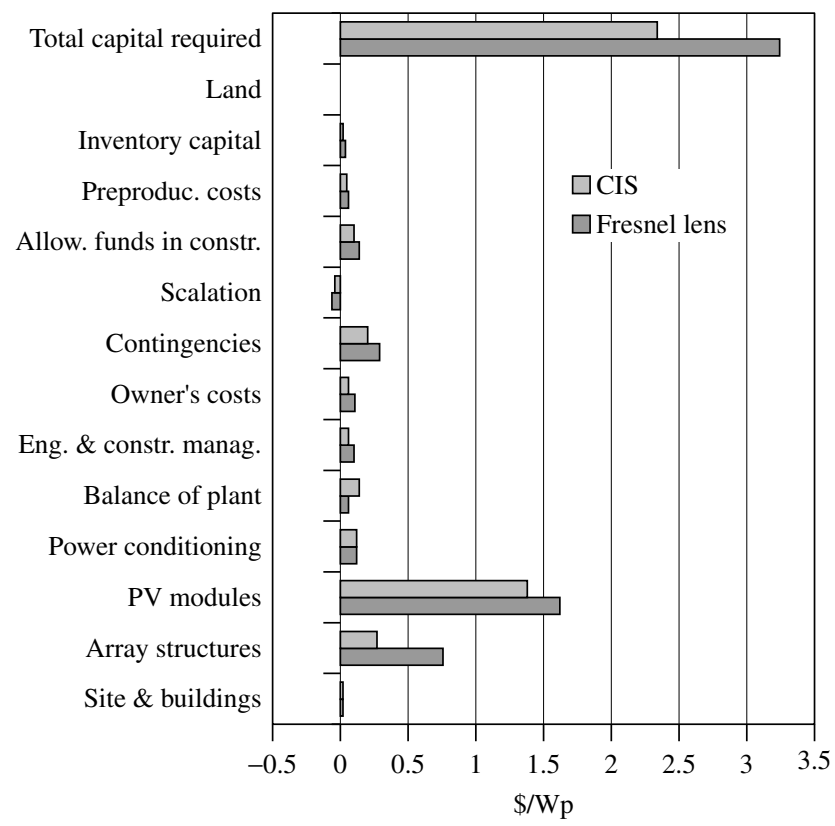

Figure 1.14 Calculated breakdown of costs of the construction of a PV central plant based on two anticipated technologies. Above, CIS flat module cells; below, Fresnel lens concentrator with Si cells operating at 500 suns. (Data from Whisnant et al. in Chapter 21)

We present in Figure 1.15 a calculation of costs of different types of modules in an advanced manufacturing process calculated with the same procedure. Again, the origin of this is Chapter 21, devoted to cost calculations. Although cost calculations for the $\mathrm{Cu}(\mathrm{InGa}) \mathrm{Se}_{2}$ technology is not available, their costs are not expected to be too different to those of a-Si. Indeed, the cost model in Chapter 21 includes many more parameters and assumptions and the results depend on such choices. Nevertheless, according to the model, the common c-Si Cz module (with efficiency of about 14 to $15 \%$ ) is clearly more expensive than any one of the other options (provided they have a minimal efficiency of 5 to $7 \%$ ). Dendritic web technology refers to one form of Si ribbon technology that is starting to find a place in the market.

Using again the cost model in Chapter 21 we can calculate the cost of the electricity generated. Table 1.4 shows the difference of electric output of the two equally rated plants. ${ }^{2}$ Obviously, the yearly efficiency (referred to as the module aperture area) is different. Furthermore, they both present different capacity factors as defined by the ratio of the produced energy (in $\mathrm{kWh}$ or $\mathrm{MWh}$ ) to the rated power (in $\mathrm{kWp}$ or MWp) times the total number of hours in a year $(365 \times 24)$. To calculate the electricity cost (in $\$ / \mathrm{kWh})$, one term is the financial cost of all the expenditures and another much smaller one is the operation and maintenance costs (very small as stated at the beginning). The price per $\mathrm{kWh}$ must be compared to the typical average price of $\$ 0.05 / \mathrm{kWh}$ for conventional

${ }^{2}$ Figure 1.15 and Table 1.4 present cost data scaled to 1985 or 1990 equivalent dollars, as does discussion and results in Chapter 21. Although quantitatively "out of date", they are still quite useful for relative comparison. 


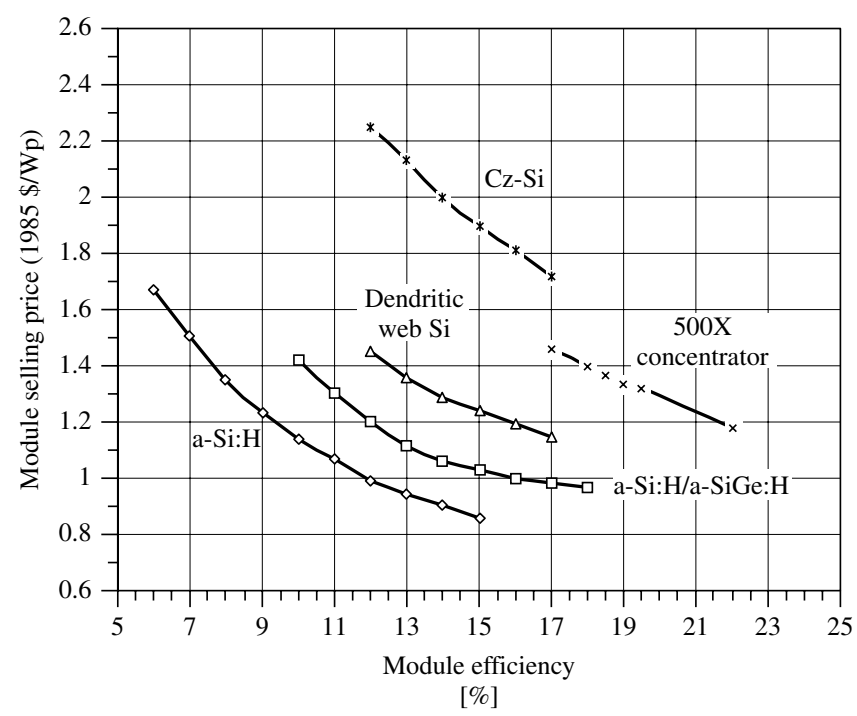

Figure 1.15 Effect of cell technology and efficiency on module price. (Source: Whisnant et al. in Chapter 21)

Table 1.4 Annual performance and energy cost summary for central station plants. Calculations for constant $1990 \$$, for a $50 \mathrm{Mw}_{\mathrm{p}}$ plant in Central California, USA. Source Whisnant et al., Chapter 21

\begin{tabular}{lcc}
\hline & $\begin{array}{c}\text { Fresnel } \\
\text { lens concentrator }\end{array}$ & $\begin{array}{c}\text { CIS } \\
\text { Flat-plate }\end{array}$ \\
\hline Energy output $(\mathrm{MWh})$ & 140100 & 112000 \\
Capacity factor & $32.0 \%$ & $25.8 \%$ \\
Annual energy efficiency & $18.8 \%$ & $9.9 \%$ \\
Annual expenses $\left(\$ 10^{6}\right)$ & & \\
$\quad$ Capital charge & 16.69 & 11.95 \\
Operation \& maintenance expense & 0.61 & 0.18 \\
Total & 17.30 & 12.13 \\
30-YR Levelized energy cost $(\$ / \mathrm{kWh})$ & & \\
Capital charge & 0.119 & 0.106 \\
Operation \& maintenance costs & 0.004 & 0.002 \\
Total $(\$ / \mathrm{kWh})$ & 0.123 & 0.106 \\
\hline
\end{tabular}

electricity. Photovoltaics is more than twice as expensive. However, this cost can be attractive for a part of the electricity generated by a utility, such as when it meets peak power demand.

For the end-user, the cost of the conventional electricity can be very similar to the one in the table. The cost of installing a PV grid-connected system in a house or building is not much more expensive than the centralized power plant presented in the table but the marketing cost of this distributed residential product will increase the final installation cost. It is to be stressed, that the costs used here are merely an indication 
of the relative significance of various factors. These assumptions and model parameters may not apply to some immature or as-yet undeveloped technologies. Yet, these exercises can be useful to decision makers, especially if complemented by sensitivity studies (as in Chapter 21).

As a final comment, the costs presented in this section are final costs calculated by a detailed account of all the elements utilized in a plant or module and an estimation of the performances achieved. In contrast, the costs in Section 1.5 are based on fundamental economic laws that are found empirically to occur regardless of technological details, yielding costs as a function of the time. Thus, the costs, as calculated in the present section, may be considered as a point of that curve, to occur somewhere in the future.

Of course, all components in the system have some parasitic power loss. Yearly average AC efficiencies of $10 \%$ are common in a well-managed grid-connected system with modules starting at $14 \%$. Much of this loss can be attributed to temperature: cells operate at 20 to $30^{\circ} \mathrm{C}$ over the ambient which reduces their efficiency and output since efficiency decreases with temperature (except for a-Si). Additionally, 8 to $10 \%$ relative losses are expected for the DC-AC conversion in the inverter. Round trip battery losses (charge-discharge) in stand-alone applications can be an additional relative 10 to $20 \%$.

\subsection{FUTURE OF EMERGING PV TECHNOLOGIES}

The solar resource is huge although its energy density is rather low. However, it is not so low as to lose any hope of massive utilization but it is not high enough to make it easy.

Obviously, the proper strategy for recovering a dispersed resource is to do it with high efficiency at a low cost per area. But the standard PV-effect, as described in this chapter, only delivers to the external circuit with high efficiency those charge carriers generated by the few photons with energy close to the band gap. The excess energy of photons whose energy is greater than the band gap is typically wasted as heat. Even worse, all of the energy of the photons whose energy is below the band gap is wasted since they are not absorbed and therefore generate no charge carriers.

Thus, as described in detail in Chapter 4, the maximum efficiency that can be obtained under the best conditions from a single junction solar cell is in the range of $40 \%$. The best efficiency so far obtained for single-junction solar cells is $27.6 \%$, with GaAs research-type cells [75] under concentrated sunlight of 255 suns, that is, of 255 times the unconcentrated standard power density (i.e. at $255 \mathrm{~kW} / \mathrm{m}^{2}$ ). Typical commercial silicon cell efficiency is $\sim 15 \%$ measured at standard conditions (input optical power density of $1 \mathrm{~kW} / \mathrm{m}^{2}, 25^{\circ} \mathrm{C}$ and standard terrestrial solar spectrum).

One way of extracting more power from the sun is to use stacks of cells of semiconductors having different band gaps. Higher band gap semiconductors are located on top of the stack allowing photons of energy less than their band gap to pass through, where they can be absorbed by inner cells of lower band gap. The limit efficiency of these stacks, as presented in Chapter 4, with infinite number of cells of different band gap is $86 \%$, as compared with the $40 \%$ of the single band gap cells. Efficiencies up to $32 \%$ (under standard unconcentrated terrestrial solar spectrum) have been achieved for a monolithic three band gap stacked cells of GaInP/GaAs/Ge [76]. 
The interest in multijunction cells has been reawakened by the requirements of space cells, where price is less relevant than the performance in many cases (Chapter 10). However, they can be used in terrestrial applications provided they are operating at very high concentration. There is a trend to develop cells operating at 1000 suns. Efficiencies up to $26 \%$ with a single band gap GaAs solar cell [77] and of over $29 \%$ with a double band gap GaInP/GaAs cells [78] have been achieved (Chapter 9). Also, the development of low-cost concentrators able to operate at 1000 suns is a subject of current research [79]. The prospects are very promising because such technologies predict in the long-term to produce electricity competitive with conventional sources. A cost estimate is presented in Table 1.5. In the 1-J no learning case, the costs are similar to those in Table 1.4. However, in the learning case the costs are, in extremely good locations (EGL), very competitive with conventional electricity, provided that we achieve very high efficiencies. In this calculation, the experience factor for the cells is the same as in microelectronics; for the rest of the elements the learning curve is same as the present one for modules [80].

The role of the experience factor has been stressed when describing Figures 1.6 and 1.7. Conventional cells have a relatively low experience factor, we think, because they are limited in the maximum efficiency they can reach. Multijunction cells, in contrast, have a much higher efficiency limit and therefore they can progress in efficiency for a longer time. This is one reason to attribute to them a faster experience factor.

Multijunction cells are also crucial to the success of the thin-film photovoltaics. In the a-Si thin-film PV technology, the highest cell and module efficiencies being reported for the past decade are for triple junctions as described in Chapter 12. The use of multijunction cells in thin films might lead to a faster learning curve and hence reduced costs. The band gap of various polycrystalline alloys of $\mathrm{Cu}(\mathrm{InGa}) \mathrm{Se}_{2}, \mathrm{Cu}(\mathrm{InAl}) \mathrm{Se}_{2}$, $\mathrm{Cu}(\mathrm{InGa})(\mathrm{SeS})$, or $\mathrm{CdZnTe}$ can be varied with alloying. The theoretical efficiency of a tandem device with a 1.6 to $1.8 \mathrm{eV}$ band gap top cell and a 1.0 to $1.2 \mathrm{eV}$ band gap bottom cell exceeds $30 \%$. In all cases, the top cell must provide the majority of the power.

Table 1.5 Costs for very high-efficiency 1000 suns-concentrating systems [80] for one junction (1-J) and four junctions (4-J) cells. NDI stands for Normal Direct Irradiation. EGL stands for extremely good location with NDI $=2700 \mathrm{~W} \cdot \mathrm{m}^{-2} \cdot$ year $^{-1}$. "No learning" means with present costs (2002) while "learning" means they are reduced by a learning curve with experience factor of 0.32

\begin{tabular}{lcc}
\hline Cost element & $\begin{array}{c}\text { 1-J, } \\
\text { no learning }\end{array}$ & $\begin{array}{c}4-\mathrm{J}, \\
\text { learning }\end{array}$ \\
\hline Cells $\left(\$\right.$ per $\mathrm{cm}^{2}$ cell area) & 13.4 & 4.43 \\
Module (\$ per aperture area) & 265 & 113 \\
Cell efficiency $(\%)$ & 23.1 & 45 \\
Module efficiency $(\%)$ & 19.0 & 37.1 \\
Plant price $\left(\$\right.$ per $\mathrm{m}^{2}$ aperture area) & 526 & 271 \\
Madrid NDI $\left(\mathrm{W} \cdot \mathrm{m}^{-2} \cdot\right.$ year $^{-1}$ ) & 1826 & 1826 \\
Performance ratio & 0.606 & 0.606 \\
Electricity costs in Madrid $(\$$ per $\mathrm{kWh})$ & 0.186 & 0.050 \\
Electricity costs in EGL $(\$$ per $\mathrm{kWh})$ & 0.131 & 0.035 \\
\hline
\end{tabular}


Yet, in all these alloy systems, material quality and device performance degrades substantially for band gaps exceeding 1.4 to $1.6 \mathrm{eV}$, depending on the materials (see Chapter 13). A very productive area for research will be to either improve these materials when they are produced with high band gaps or to develop new alloys. Any multijunction process must be sequentially compatible from beginning to end.

Besides the multijunction effort, other concepts are in place for attempting a better utilization of the solar spectrum, such as the Intermediate Band (IB) concept [81], which is described further in Chapter 4. A band, with electron states in the center of the band gap, would permit the passage of electrons from the valence band to the conduction band by means of two low-energy photons, one pumping electrons from the valence to the intermediate band and the other pumping the electron from this band to the conduction band. This concept presents a potential behavior which is somewhat better than the multijunction cell stack with two semiconductors. Nanotechnology is a means of producing this intermediate band [82], and the basic effect sketched above seems to have been proved already by using quantum dots [83]. Quantum dots are droplets of one material in a host of another material of higher band gap. The droplets are very small and exhibit quantum effects among which is the appearance of intermediate bands or levels. Alloys might also be found with intermediate band [84], but no practical realization of this concept has been shown so far. Other new type devices, although not easy to realize today, are also envisioned. The theoretical basis of all these new devices can be found in Chapter 4.

Finally, solar cells have been constructed which do not operate on the photovoltaic effect but on charge transfer between molecular orbitals, as in photosynthesis. Their potential for efficient absorption of the spectrum depends on "tuning" the chemistry of organic dyes, as described in Chapter 15. Presently the subject of much research, dyesensitized solar cells have achieved $>10 \%$ efficiency but have many challenges regarding stability and manufacturability.

\subsection{CONCLUSIONS}

Photovoltaics constitutes a new form of producing electric energy that is environmentally clean and very modular. In stand-alone installations, it must use storage or another type of generator to provide electricity when the sun is not shining. In grid-connected installations storage is not necessary: in the absence of sunlight, electricity is provided from other (conventional) sources.

PV electricity is highly appreciated by the public. It is unique for many applications of high social value such as providing electricity to people who lack it in remote areas. Often, international donor agencies are providing the funding, as many of the users are very poor. Photovoltaics is very suitable as the power supply for remote communication equipment. Its use is increasing rapidly to produce electricity in grid-connected houses and buildings in industrialized countries, despite a 5 to 10 times higher cost than conventional electricity. Often, publicly funded programs are required to enable photovoltaics to compete by partially offsetting its higher costs.

Largely, because of grid-connected PV applications such as homes and businesses, the expansion of the PV market has been very rapid in the last years of the twentieth 
century and it is expected to continue during the next few years of the twenty-first century. Then, the growth will probably continue at a slower pace unless new technological advances are developed and commercialized. In that case, growth could accelerate.

Photovoltaics is poised to become a large global high-tech industry, manufacturing and selling modules in nearly every country. Governments and entrepreneurs should be aware of this. Public R\&D support has always been generous. It must continue to be so for those countries that want to maintain leadership in this technology. Partial subsidization of PV installations is permitting an unprecedented development of the PV industry and will also help the industry of the countries involved in this endeavor to take the lead.

Crystalline Si technology, both monocrystalline and multicrystalline is today clearly dominant, with about $90 \%$ of the market. It will remain dominant at least for the next ten years. The trend is towards the multicrystalline option. Si is one of the most abundant elements in the Earth's crust but the purified Si used in today's solar cells is obtained primarily as off-grade poly-Si and scrap wafers from the microelectronic industry. Soon it will not be enough for the growing PV industry. Thus, some concerns exist regarding a shortage of the purified silicon for the PV industry. However, it is doubtful that Si technology will be able to reach competition with conventional electricity. Consequently, low-cost alternatives and high-efficiency novel concepts, many already in development, are needed.

Thin-film technology is one of the candidates to take over from Si technology in the long-term. There are many technological options regarding thin-film materials and methods of deposition but their primary claim to the throne currently occupied by $\mathrm{Si}$ is that they can be ultimately produced at much lower cost.

Concentration of sunlight is another candidate for mass penetration of photovoltaics, although it will not be easily accepted for the grid-connected houses, one of the most promising applications today. Concentrators will probably find incipient niche markets in big stand-alone applications or as small, central-power plants during the present decade.

Finally, new materials and device designs based on III-V semiconductor alloys, such as GaInP allowing more efficient use of the solar spectrum are now being developed for space applications. With the use of concentrators, they may be of interest for terrestrial applications, with the potential of reaching competitive costs with conventional electricity. Other options, such as quantum dots and dye-sensitized solar cells, are still in the initial research phase. They must compete not only with the ubiquitous Si but also with the other options, mentioned above for funding for further development.

Thus, photovoltaics possesses a panoply of novel technologies that almost ensures that alternatives will be available when the current Si wafer technology cannot reach prices low enough to compete with conventional electricity. If this happens, a strong industry and infrastructure - first developed for the Si technology - will be able to seamlessly take this new PV technology and apply it worldwide. In any case, the present "subsidies" to research or application must be considered as public investment in a policy with strong public support and long-term human benefits.

The widespread contribution of PV electricity in electric grids will require a new type of grid management that can accept small generators as well as small consumers. On 
the other hand, hybrid forms of electricity generation, including photovoltaics, will play an important role in the future development of stand-alone applications and minigrids. The general cost reduction will make photovoltaics available to more and more people in developing countries helping their development with little degradation of air quality associated with fossil-fuel generators.

In summary, it is very likely that photovoltaics will become in the next half century an important source of world electricity. Public support and global environmental concerns will keep photovoltaics viable, visible, and vigorous both in new technical developments and user applications. Nations which encourage photovoltaics will be leaders in this shining new technology, leading the way to a cleaner, more equitable twenty-first century, while those that ignore or suppress photovoltaics will be left behind in the green, economic energy revolution.

\section{REFERENCES}

1. Benka S, Phys. Today 38, 39 (2002); adapted from Pasternak A, Lawrence Livermore Natl. Lab report UCRL_ID_140773 (October 2000).

2. We acknowledge Dr. Larry Kazmerski of NREL, and coauthor of Chap. 24, for developing the "myths of PV" concept as a way of dispelling common misunderstandings and issues in PV. See his paper Renewable Energy World, August 2002, 175-183.

3. "Energy System Emissions and Material Requirements", Meridian Corporation (Alexandria VA) report prepared for the Deputy Assistant Secretary for Renewable Energy of the USA (1989).

4. Kelly H, Weinberg C, in Johansson T et al. (Eds), Renewable Energy, 1011-1069, Island Press, Washington, DC (1993).

5. Maycock P, Renewable Energy World 3, 59-74 (2000).

6. Fthenakis V, Moskowitz P, Prog. Photovolt. 8, 27-38 (2000).

7. Tsou Y et al., Proc. $2^{\text {nd }}$ World Conf. Photovoltaic Energy Conversion, 1199-1204 (1998).

8. See Papers contained in Proc. of Photovoltaic Safety Conf., Sol. Cells 19, 189-397 (1987).

9. See Papers contained in Proc. of Workshop on Environmental Aspects of PV Systems, Prog. Photovolt. 6, 87-146 (1998).

10. www.pv.bnl.gov.

11. Fthenakis V, Moskowitz P, Prog. Photovolt. 3, 295-306 (1995).

12. Patterson M, Turner A, Sadeghi M, Marshall R, Proc. $12^{\text {th }}$ Euro Photovoltaic Solar Energy Conf., 951-953 (1994).

13. Fthenakis V et al., Prog. Photovolt. 7, 489-497 (1999).

14. Bohland J, Smigielski K, Proc. 28 ${ }^{\text {th }}$ IEEE Photovoltaic Specialist Conf., 575-578 (2000).

15. Moskowitz P, Fthenakis V, Sol. Cells 31, 513-525 (1993).

16. Moscowitz P, Fthenakis V, Sol. Cells 29, 63-71 (1990).

17. Fthanakis V, Eberspacher C, Moskowitz P, Prog. Photovolt. 4, 447-456 (1996).

18. Bohland J, Dapkus T, Kamm K, Proc. $2^{\text {nd }}$ IEEE World Photovoltaic Specialists Conf., 716-719 (1998).

19. Alsema E, Prog. Photovolt. 8, 17-25 (2000).

20. Keoleian G, Lewis G, Prog. Photovolt. 5, 287-300 (1997).

21. Knapp K, Jester T, $16^{\text {th }}$ Euro Photovoltaic Solar Energy Conf., 2053-2056 (2000).

22. Fritts C, Proc. Am. Assoc. Adv. Sci. 33, 97 (1883).

23. Chapin D, Fuller C, Pearson G, J. Appl. Phys. 25, 676, 677 (1954).

24. Reynolds D, Leies G, Antes L, Marburger R, Phys. Rev. 96, 533, 534 (1954).

25. Jenny D, Loferski J, Rappaport P, Phys. Rev. 101, 1208, 1209 (1956).

26. Prince M, J. Appl. Phys. 26, 534-540 (1955). 
27. Loferski J, J. Appl. Phys. 27, 777-784 (1956).

28. Wysocki J, Rappaport P, J. Appl. Phys. 31, 571-578 (1960).

29. Shockley W, Queisser H, J. Appl. Phys. 32, 510-519 (1961).

30. Cusano D, Solid State Electron. 6, 217-232 (1963).

31. Wysocki J et al., Appl. Phys. Lett. 9, 44-46 (1966).

32. Alferov ZhI, Fiz. Tekh. Poluprovodn. 4, 2378 (1970).

33. Lindmayer J, Allsion J, COMSAT Tech. Rev. 3, 1-22 (1973).

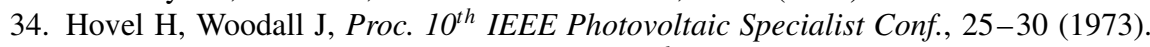

35. Sumner D, Whitaker C, Schlueter L, Proc. $20^{\text {th }}$ IEEE Photovoltaic Specialist Conf., 1289-1292 (1988).

36. Green M et al., Proc. 18 $8^{\text {th }}$ IEEE Photovoltaic Specialist Conf., 39-42 (1985).

37. Sinton R, Kwark Y, Gruenbaum P, Swanson R, Proc. $18^{\text {th }}$ IEEE Photovoltaic Specialist Conf., 61-65 (1985).

38. Friedman D et al., Prog. Photovolt. 3, 47 (1995).

39. Gratzel M, Prog. Photovolt. 8, 171-186 (2000).

40. Contreras M et al., Prog. Photovolt. 7, 311-316 (1999).

41. Bower W, Prog. Photovolt. 8, 113-126 (2000).

42. Fitzgerald M, Mrohs M, Proc. 26 ${ }^{\text {th }}$ IEEE Photovoltaic Specialist Conf., 1225-1229 (1997).

43. Nieuwenhout F et al., Prog. Photovolt. 9, 455-474 (2001).

44. Cabraal A, Cosgrove-Davies M, Schaeffer L, Proc. 25 ${ }^{\text {th }}$ IEEE Photovoltaic Specialist Conf., 1357-1362 (1996).

45. Hoff T, Jennings C, Proc. $18^{\text {th }}$ IEEE Photovoltaic Specialist Conf., 235-240 (1985).

46. Shugar D, Hoff T, Prog. Photovolt. 1, 233-250 (1993).

47. Byrne J, Hegedus S, Wang Y, Prog. Photovolt. 2, 235-248 (1994).

48. Yordi B, Gillett W, Prog. Photovolt. 5, 175-185 (1997).

49. Iuchi $\mathrm{M}, 2^{\text {nd }}$ World Conference and Exhibition on Photovoltaic Solar Energy Conversion, 3304-3307 (1998).

50. Strong S, Proc. 25 th IEEE Photovoltaic Specialist Conf., 1197-1202 (1996).

51. Cody G, Tiedje T, Proc. $25^{\text {th }}$ IEEE Photovoltaic Specialist Conf., 1521-1524 (1996).

52. Luque A, Prog. Photovolt. 9, 303-312 (2001).

53. Parente V, Goldemberg J, Zilles R, Prog. Photovolt. 10, 571-574 (2002).

54. Johansson T, Kelly H, Reddy A, Williams R, Renewable Energy, Chap. 1, Island Press, Washington, DC, 1-71 (1993).

55. Photon Int. 38-43 (March 2002).

56. Aulich H, Raptis F, Schmid J, Prog. Photovolt. 6, 325-340 (1998).

57. Sumner D, Whitaker C, Schlueter L, Proc. $20^{\text {th }}$ IEEE Photovoltaic Specialist Conf., 1289-1292 (1988).

58. Wenger H, Jennings C, Ianucci J, Proc. $21^{\text {st }}$ IEEE Photovoltaic Specialist Conf., 844-849 (1990).

59. Iliceto A, Belli G, Lambri L, Toninelli F, Proc. $14^{\text {th }}$ Euro. Photovoltaic Solar Energy Conf., 2670-2674 (1997).

60. Matlin R, Shugar D, Proc. 12 ${ }^{\text {th }}$ Euro Photovoltaic Solar Energy Conf., 842-845 (1994).

61. Sala G et al., $2^{\text {nd }}$ World Conference and Exhibition on Photovoltaic Solar Energy Conversion, 1963-1968 (1998).

62. Kardauskas M, Rosenblum M, Mackintosh B, Kalejs J, Proc. $25^{\text {th }}$ IEEE Photovoltaic Specialist Conf., 383-388 (1996).

63. Schmidt W, Woesten B, Kalejs J, Prog. Photovolt. 10, 129-140 (2002).

64. Barnett A, Rothwarf A, IEEE Trans. Electron Devices 27, 615-630 (1980).

65. Hewig G et al., Proc. 16 ${ }^{\text {th }}$ IEEE Photovoltaic Specialist Conf., 713-718 (1982).

66. Bragagnolo J et al., IEEE Trans. Electron Devices 27, 645-650 (1980).

67. Hall R, Birkmire R, Phillips J, Meakin J, Appl. Phys. Lett. 38, 925, 926 (1981).

68. Catalano A et al., Proc. $16^{\text {th }}$ IEEE Photovoltaic Specialist Conf., 1421, 1422 (1982). 
69. Mickelson R, Chen W, Proc. 16 $6^{\text {th }}$ IEEE Photovoltaic Specialist Conf., 781-785 (1982).

70. Tyan Y, Perez-Albuerne E, Proc. 16 ${ }^{\text {th }}$ IEEE Photovoltaic Specialist Conf., 794-799 (1982).

71. Phillips J, Birkmire R, Lasswell P, Proc. $16^{\text {th }}$ IEEE Photovoltaic Specialist Conf., 719-722 (1982).

72. Maycock P, PV NEWS 21(4), 1 (April 2002).

73. Wills R, Hall F, Strong S, Wohlgemuth J, Proc. 25 th IEEE Photovoltaic Specialist Conf., 1231-1234 (1996).

74. Knaupp W et al., Proc. $25^{\text {th }}$ IEEE Photovoltaic Specialist Conf., 1235-1238 (1996).

75. Vernon S et al., Proc. 22 ${ }^{\text {nd }}$ IEEE Photovoltaic Specialist Conf., 353-357 (1991).

76. Cotal H et al., Proc. $28^{\text {th }}$ IEEE Photovoltaic Specialist Conf., 955 (2000).

77. Algora C et al., IEEE Trans. Electron Devices 48, 840-844 (2001).

78. Bett A et al., Proc. $28^{\text {th }}$ IEEE Photovoltaic Specialist Conf., 961 (2000).

79. Miñano J, González J, Benítez P, Appl. Opt. 34, 7850 (1995).

80. Yamaguchi M, Luque A, IEEE Trans. Electron Devices 46(10), 2139-2144 (1999).

81. Luque A, Martí A, Phys. Rev. Lett. 78(26), 5014-5017 (1997).

82. Martí A, Cuadra L, Luque A, Proc. 28 $8^{\text {th }}$ IEEE Photovoltaic Specialist Conf., 940-943 (2000).

83. Cassaboisa G et al., Physica E13, 105-108 (2002).

84. Wahnon P, Tablero C, Phys. Rev. B 65, 165115-1-165115-10 (2002). 
